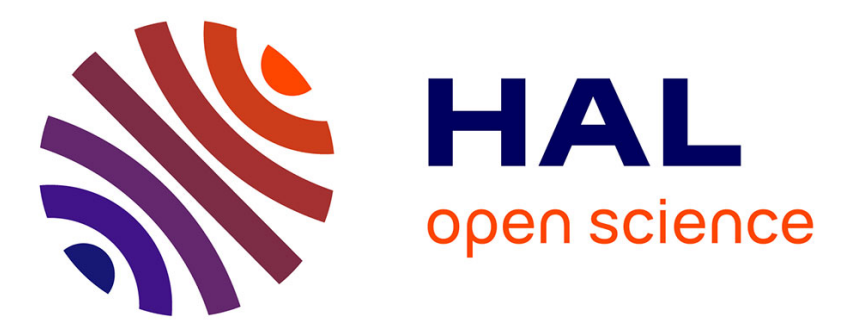

\title{
Monomolecular Cracking Rates of Light Alkanes over Zeolites Determined by IR Operando Spectroscopy
}

\author{
Haoguang Li, Shashikant A Kadam, Alexandre Vimont, Richard F
}

Wormsbecher, Arnaud Travert

\section{To cite this version:}

Haoguang Li, Shashikant A Kadam, Alexandre Vimont, Richard F Wormsbecher, Arnaud Travert. Monomolecular Cracking Rates of Light Alkanes over Zeolites Determined by IR Operando Spectroscopy. ACS Catalysis, 2016, 6 (7), pp.4536-4548. 10.1021/acscatal.6b01025 . hal-02162186

\author{
HAL Id: hal-02162186 \\ https://hal.science/hal-02162186
}

Submitted on 21 Jun 2019

HAL is a multi-disciplinary open access archive for the deposit and dissemination of scientific research documents, whether they are published or not. The documents may come from teaching and research institutions in France or abroad, or from public or private research centers.
L'archive ouverte pluridisciplinaire $\mathbf{H A L}$, est destinée au dépôt et à la diffusion de documents scientifiques de niveau recherche, publiés ou non, émanant des établissements d'enseignement et de recherche français ou étrangers, des laboratoires publics ou privés. 


\section{Monomolecular Cracking Rates of Light Alkanes}

\section{over Zeolites Determined by IR Operando}

\section{Spectroscopy}

Haoguang Li, ${ }^{\dagger, \star}$ Shashikant A. Kadam, ${ }^{\dagger, \star}$ Alexandre Vimont ${ }^{\dagger}$ Richard F. Wormsbecher ${ }^{\dagger, t,}$ and Arnaud Travert ${ }^{* *}$

$\dagger$ Normandie Univ, ENSICAEN, UNICAEN, CNRS, Laboratoire Catalyse et Spectrochimie, 14000 Caen, France

$\$$ Department of Chemistry and Biochemistry, University of Maryland Baltimore County, MD, 21250 USA

$\S$ W.R. Grace and Co., Columbia, MD, 21044 USA.

KEYWORDS. Alkane, Zeolites, IR Operando spectroscopy, Adsorption enthalpy, Adsorption entropy, Apparent rates, Intrinsic activation entropy.

ABSTRACT. The coverage of H-MFI zeolite acid sites by light alkanes $\left(\mathrm{C}_{3}-\mathrm{C}_{7}\right)$ at monomolecular cracking reaction conditions was determined using infrared operando spectroscopy. At such conditions, alkane adsorption through H-bonding leads to a fully reversible perturbation of the zeolite $\mathrm{vOH}$ band at $3600 \mathrm{~cm}^{-1}$. This was used to assess the coverage at various temperatures and pressures, allowing for the determination of the adsorption thermodynamic parameters at reaction 
conditions. The simultaneous determination of apparent monomolecular cracking rate constants allowed for the direct determination of the intrinsic cracking rate constants, activation energies, and activation entropies. These results show that while the coverage of the active sites increases with the alkane size, the differences tend to decrease at high temperature because of entropic effects. The intrinsic activation energy was constant for all alkanes investigated in this study ( $190 \mathrm{kJmol}^{-1}$ ), lying in the lower range of the values usually derived from alkane adsorption heats and apparent activation energies. The magnitude of the activation entropies obtained in the present study was also lower than those derived from low temperature adsorption measurements, indicating that temperature could increase the entropy of the adsorbed state. However, this decrease was much less dramatic than that predicted by recent state of art simulations. In any case, this operando study confirms that the activation entropy chiefly determines the variations of apparent protolytic cracking rates.

\section{INTRODUCTION}

Acidic zeolites play a central role in petrochemical refining. In particular they catalyze cracking of alkanes, a major reaction in the production of fuels from crude oil by fluid catalytic cracking. ${ }^{1-3}$ At low conversion, these reactions mostly occur through monomolecular cracking, where the alkane is protonated by a zeolite acid site and undergoes subsequent $\mathrm{C}-\mathrm{C}$ bond scission. ${ }^{4-5}$ Mechanistic studies of these reactions are complicated by the interplay between adsorption thermodynamics, which governs the concentration of alkane-active sites complexes, and the bond-breaking kinetics of these complexes. As a first order reaction, the specific rate of monomolecular cracking is given by: 


$$
r=L k_{a p p} P
$$

where $L$ is the concentration of active sites $(\mathrm{L}=[\mathrm{ZOH}]$, the concentration of acidic bridged $\mathrm{OH}$ groups of the bare zeolite), $k_{a p p}$ is the apparent rate constant per active site (turnover frequency) per unit alkane pressure, and $P$ the alkane partial pressure. For a monomolecular reaction, the rate can equivalently be expressed as:

$$
r=k_{\text {int }}[\mathrm{ZOH} \cdots \mathrm{A}]
$$

where $[\mathrm{ZOH} \cdots \mathrm{A}]$ is the concentration of alkane-active site adsorption complexes at reaction condition and $k_{\text {int }}$ is the intrinsic rate constant of the cracking reaction. Under the conditions of monomolecular cracking, the adsorption of products can be neglected. Hence, the concentration of alkane-active site adsorption complexes is given by the Henry's law:

$$
[\mathrm{ZOH} \cdots \mathrm{A}]=L K_{a d s}^{\circ} P / P^{\circ}
$$

where $K_{a d s}^{\circ}$ is the alkane adsorption constant on the active site and $P^{\circ}$ is the pressure of the standard state. Equations (1-3) thus show that conventional catalytic activity testing only allows for the determination of the apparent cracking rate constant $k_{a p p}$ which lumps the alkane adsorption equilibrium constant $K_{a d s}^{\circ}$ and the intrinsic rate constant $k_{\text {int }}$ :

$$
k_{a p p}=K_{a d s}^{\circ} \times k_{\text {int }}
$$

The adsorption equilibrium constant $\left(K_{a d s}^{\circ}\right)$ and the intrinsic rate constant $\left(k_{\text {int }}\right)$ are in turn related to their enthalpic and entropic parameters through the general relationship of the equilibrium constant to the standard Gibbs free energy $\left(K_{a d s}^{\circ}=\exp \left(-\Delta_{a d s} G^{\circ} / R T\right)\right)$ and the Eyring equation, respectively. Hence: 


$$
k_{a p p}=\exp \left(-\frac{\Delta_{a d s} H^{\circ}}{R T}\right) \exp \left(\frac{\Delta_{a d s} S^{\circ}}{R}\right) \times \frac{k_{B} T}{h} \exp \left(-\frac{\Delta H^{\ddagger}}{R T}\right) \exp \left(\frac{\Delta S^{\ddagger}}{R}\right)
$$

Experimentally, the temperature dependence of the apparent rate constant is generally used to assess the apparent activation energy $\left(E_{a p p}\right)$ and the pre-exponential factor $A_{a p p}$ defined by the Arrhenius law:

$$
k_{a p p}=A_{a p p} \exp \left(-\frac{E_{a p p}}{R T}\right)
$$

Identification of equations (5) and (6) above using the logarithmic derivatives of $k_{a p p}$ with respect to $1 / \mathrm{T}$ finally yields the following relationships:

$$
\begin{gathered}
E_{a p p}=\Delta H^{\ddagger}+R T+\Delta_{a d s} H=E_{a}+\Delta_{\mathrm{ads}} H \\
A_{a p p}=v\left(\frac{\Delta S_{a p p}^{\ddagger}}{R}\right)=v \exp \left(\frac{\Delta_{\mathrm{ads}} S}{R}\right) \exp \left(\frac{\Delta S^{\ddagger}}{R}\right)
\end{gathered}
$$

where $E_{\mathrm{a}}=\Delta H^{\ddagger}+R T$ is usually called 'intrinsic' or 'true' activation energy of reaction (Eqn. 7), $v=k_{B} T e / h$, is a constant independent of the chemical system investigated, and $\Delta S_{a p p}^{\ddagger}$ is the apparent activation entropy.

Currently, the experimental determination of the intrinsic rate parameters, the activation energy $E_{a}$ (or equivalently the activation enthalpy $\Delta H^{\ddagger}$ ) and activation entropy $\Delta S^{\ddagger}$ requires an independent evaluation of the adsorption parameters $\Delta_{\text {ads }} H$ and $\Delta_{\text {ads }} S$ using extrapolation from low temperature adsorption measurements. ${ }^{6-9}$

While it is well known that apparent cracking rate constants are strongly dependent on the alkane size and on the zeolite structure, the intrinsic activation energies, derived from apparent activation energies of the reaction and the alkane adsorption heat measured at low temperature are nearly constant, of the order of $195 \mathrm{~kJ} \mathrm{~mol}^{-1} .{ }^{4,10-14}$ On this basis, the variations of apparent rates were initially accounted by changes in the adsorption equilibrium constant, i.e. to the 
concentration of adsorbed alkanes. ${ }^{4,10,12}$ More recently, however, Iglesia and co-workers ${ }^{9,15-16}$ have pointed out that owing to adsorption enthalpy-entropy compensation, ${ }^{8,12}$ the concentration of adsorbed alkanes of different sizes is not expected to change much at reaction temperatures and have concluded that apparent rates are chiefly determined by the pre-exponential factor of the intrinsic rate constant, or activation entropy, $\Delta S^{\ddagger} .9,15-16$

Recently, many theoretical studies have been performed to better understand how coverage and intrinsic kinetics govern the alkane reactivity. De Moor et al. ${ }^{17}$ used hybrid QM/MM calculations and standard statistical thermodynamics to assess the adsorption parameters at reaction temperature. The values thus obtained were consistent with those derived from low temperature experiments. However, ab initio molecular dynamic studies by Bučko et al. ${ }^{18}$ and Jiang et al. ${ }^{19}$, as well as Monte Carlo simulations by Tranca et al. ${ }^{20}$ and Janda et al. ${ }^{21-22}$ have pointed out an important influence of temperature on the adsorption parameters. In particular, they often report adsorption entropies $\left(\Delta_{a d s} S\right)$ of smaller magnitude than those determined at low temperature. ${ }^{6,9}$ In turn, some of these theoretical studies have predicted activation entropies of much lower magnitude (by a factor $\sim 2-3$ depending on the alkane) than those derived from combination of experimental apparent rates and low temperature adsorption measurements (Eqn. 8). ${ }^{18,20}$ This was primarily accounted by the fact that these theoretical studies consider a larger configuration space for the reactant state, where the alkane does not always interact with the acid site. On the other hand, at the experimental conditions used for the assessment of the adsorption parameters, most alkane molecules are localized over Brønsted acid sites. ${ }^{18,20}$ More recently, Janda et al. ${ }^{21-22}$ have reassessed alkane adsorption parameters using Monte Carlo simulations by specifically considering configuration spaces at the vicinity of the acid sites. This has led to a much better agreement between adsorption parameters derived from experiment and simulation. 
However, while earlier theoretical studies confirmed that the increase of apparent rates with the alkane chain length are primarily due to changes in activation entropy, ${ }^{17,20}$ recent Monte Carlo simulation of Janda and co-workers have led to the conclusion that it is primarily caused by a decrease of activation enthalpy $\Delta H^{\star}$ with the alkane chain length. ${ }^{21}$

Thus, the origin of activity trends in protolytic cracking of light alkanes still appears controversial. Among the factors put forward by theoretical studies to explain such discrepancies, the temperature dependence of adsorption enthalpies and entropies, which is neglected in the evaluation of activation entropies from experimental data, is expected to play a major role. ${ }^{18-22}$ Hence, the determination of the coverage of the zeolite active sites at reaction conditions, which has never been done to our knowledge, is key for the quantitative determination of the monomolecular reaction parameters.

The main objective of the present study was to determine experimentally the coverage of the acid sites of H-MFI zeolites by light alkanes (propane, n-butane, n-pentane, n-hexane and nheptane) at monomolecular cracking reaction conditions simultaneously with the kinetics of the cracking reaction. This was done in an operando IR reactor-cell ${ }^{23-24}$ at variable temperatures (600-710 K), partial pressures and contact times. This allowed for recording the IR spectra of the zeolite acidic $\mathrm{OH}$ groups interacting with the hydrocarbon in the feed. These spectroscopic data, combined with simultaneous activity measurements, were used to derive the intrinsic rate parameters, $E_{\mathrm{a}}$ and $\Delta S^{\ddagger}$, as well as the thermodynamic adsorption parameters, $\Delta_{\text {ads }} H$ and $\Delta_{\text {ads }} S$ directly at reaction conditions without the need for extrapolation. It will be shown that the activation entropy $\Delta S^{\ddagger}$ chiefly determines the variations of apparent cracking rates. Finally, the activation entropies for individual cracking reactions $\Delta S_{i}^{\ddagger}$ were derived from the corresponding 
selectivities and were used to gain insight of the alkane internal degrees of freedom involved in the transition state.

\section{EXPERIMENTAL}

Three commercial H-MFI zeolites with different framework Si/Al ratios (20, 29 and 75), denoted $\mathrm{H}-\mathrm{MFI}(\mathrm{xx})$ in the following where $\mathrm{xx}$ is the $\mathrm{Si} / \mathrm{Al}$ ratio, were used. No significant amount of extra-framework aluminum was detected by ${ }^{27} \mathrm{Al} \mathrm{NMR}$ or pyridine adsorption followed by infrared spectroscopy (see Supporting Information for supplementary details). About $20 \mathrm{mg}$ of zeolite powder was pressed into a self-supported wafer with a surface of $2 \mathrm{~cm}^{2}$. The wafer was loaded into a transmission operando IR reactor-cell. ${ }^{23-24}$ Before testing, the zeolite wafer was activated at $750 \mathrm{~K}$ under a flow of $25 \mathrm{cc} /$ min mixed gas $\left(90 \% \mathrm{~N}_{2}\right.$ and $\left.10 \% \mathrm{O}_{2}\right)$ for 5 hours. The infrared absorption coefficient of the band characteristic of the acidic $\mathrm{OH}$ groups of the zeolites was determined using a volumetric titration using pyridine as a basic probe molecule. The principle of this methodology has been previously reported ${ }^{25-26}$ and consists in monitoring the decrease of the $\mathrm{vOH}$ band area characteristic of the acidic $\mathrm{OH}$ groups (band at $3600 \mathrm{~cm}^{-1}$ ) upon exposure to accurate doses of pyridine which results from the protonation of pyridine by these acidic $\mathrm{OH}$ groups $\left(\mathrm{ZOH}+\mathrm{Py} \rightarrow \mathrm{ZO}^{-} \cdots \mathrm{PyH}^{+}\right)$. The slope of the curve of the $v \mathrm{OH}$ area versus amount of adsorbed pyridine yielded a $\epsilon_{O H}$ value of $3.5 \pm 0.2 \mathrm{~cm} \mathrm{\mu mol}^{-1}$, consistent with the literature. ${ }^{25}$ For consistency, the total number of Brønsted acid sites was determined by pyridine dosage. This total number of sites ( $L$, Eqn. 1$)$ determined by pyridine adsorption was found, for the three zeolites, correlated well with the total number of tetrahedral $\mathrm{Al}$ derived from the framework Si/Al ratio (NMR), yet systematically lower by $\sim 15-20 \%$. Such a precision is comparable to that obtained by $\mathrm{NH}_{3}$ dosing. ${ }^{22}$ It is worth mentioning here that a relatively low 
precision on the total number of sites has a limited impact in the value of the adsorption entropy: a relative error $\Delta L / L \sim 0.2$ leads to an absolute change of the adsorption entropy of $\sim$ $-R \ln (1-\Delta L / L) \sim 3 \mathrm{~J} \mathrm{~mol} \mathrm{~K}^{-1}$. This is of the same order as the standard error of the regression of the van't Hoff plot and much lower than the magnitude adsorption entropies (40 to $100 \mathrm{~J} \mathrm{~mol}^{-1}$ $\left.\mathrm{K}^{-1}\right)$.

The monomolecular cracking reaction of alkanes (propane, $\mathrm{n}$-butane, $n$-pentane, $n$-hexane, $n$ heptane) was carried out under atmospheric total pressure and at various temperatures (620$750 \mathrm{~K}$ ). Propane and butane were delivered from gas cylinders (Air Liquide) while pentane, hexane and heptane (Sigma Aldrich, Analytical grade) were delivered through a saturator under controlled temperature ( $293 \mathrm{~K}$ for hexane and heptane; $263 \mathrm{~K}$ for pentane) under a nitrogen flow. The partial pressures were adjusted by dilution in $\mathrm{N}_{2}$ (Air Liquide).

The products were analyzed by gas phase chromatography (HP 3800), equipped with a FID detector with an alumina column $\left(\mathrm{KCl} / \mathrm{Al}_{2} \mathrm{O}_{3}, 30 \mathrm{~m}\right.$ length, $350 \mu \mathrm{m}$ internal diameter). All the conditions (temperature, partial pressure, and contact times) were adjusted in order to control the actual total conversion below $2 \%$. The typical ranges of alkane conversions obtained in our conditions are reported in Supporting Information. At such conversions, no hydrocarbons with longer carbon chain than the reactant were detected and no deactivation with time on stream was observed. Before activity measurement, about one hour of stabilization was used at each reaction condition. The absence of deactivation was regularly checked by activity measurements at initial reaction conditions (return point).

The apparent cracking rates of alkane reactants ( $n$ carbon atoms) were computed following Narbeshuber et al. ${ }^{10}$ using: 


$$
r=\frac{F}{W} \sum_{i=1}^{n-2} y_{i}
$$

Where $F$ is the molar flow rate of alkane, $W$ is the mass of the zeolite wafer and $y_{i}$ are the molar yields of lower alkanes ( $i$ carbon atoms). In our conditions, secondary reactions such as hydrogen transfer had a limited impact and did not affect the total yield of the lower alkanes that increased linearly with the contact times or conversion ranges investigated here. This indicates that the apparent cracking rate using the above expression is not affected by secondary reactions in our conditions. A similar expression to Eqn. 9 where the sum is over the direct dehydrogenation products of the alkane reactant was used for the determination of dehydrogenation rates. The absence of external diffusion limitations in our conditions was checked by (i) using the Madon-Boudart $\operatorname{method}^{27}$ by verifying that the apparent rate constant was proportional to the zeolite content in pellets made of zeolite $(50 \%)$ - silica $(50 \%)$ mixtures, and (ii) by comparing the cracking rate constants normalized by the number of acidic $\mathrm{OH}$ groups of the zeolites with those reported in the literature (see below).

The IR analysis of the zeolite surface was carried out using a Nicolet 6700 FT-IR instrument equipped with a MCT detector at $4 \mathrm{~cm}^{-1}$ resolution. The IR spectrum of the activated zeolite was used as the reference spectrum, which was subtracted from the spectra recorded during the reaction. The difference spectra thus obtained were then corrected for the atmospheric water present in the spectrometer and gas phase alkane in the IR reactor cell. As discussed below, the intensity of the $v \mathrm{OH}$ band decreased reversibly upon alkane adsorption. The full restoration of the initial $\mathrm{vOH}$ band intensity was systematically checked after each reaction condition (e.g. fixed temperature, pressure and contact time) by shutting off the reactant flow, which allowed for ascertaining for the absence of irreversible poisoning of the acid sites during the reaction. Finally, the absence of variation in the decrease of the $\mathrm{vOH}$ band at fixed temperature and alkane 
pressure while varying the contact time (and hence the conversion and olefin yields) was also systematically checked in order to make certain that the adsorption of products did not perturb the measured intensity loss of the $\mathrm{vOH}$ band. The latter could then confidently be accounted by the reversible adsorption of the alkane reactants. The concentration of acidic $\mathrm{OH}$ groups interacting with the hydrocarbon feeds ([ZOH ... A], Eqn. 3) was then determined using the integrated intensity $I$ of the negative difference band at $3600 \mathrm{~cm}^{-1}$, and the above determined absorption coefficient $\epsilon_{O H}$ using:

$$
[\mathrm{ZOH} \ldots \mathrm{A}]=\frac{I S}{\epsilon_{O H} W}
$$

where $S$ and $W$ are the geometric surface area and the mass of the pellet, respectively.

\section{RESULTS AND DISCUSSION}

\section{Validation of the IR operando cell.}

The present study required the simultaneous determination of the coverage of the acid sites by the reactant and the reaction kinetics at differential reaction conditions. Because of the upper limit in the alkane flow rate, which was used to vary the contact time, the use of our operando system at high temperatures $(>750 \mathrm{~K})$ generally led to either measurement at too high conversions, leading to secondary reactions and coke formation with irreversible poisoning of the acid sites, or to too low coverage of the active sites by alkanes, making the accurate determination of the coverage difficult. Hence, the experiments were carried out at temperatures lower than those typically used for conventional measurements of alkane cracking rates: $\sim 600$ $710 \mathrm{~K}$ vs. 750 - $825 \mathrm{~K}$. In order to assess the kinetic relevance of our operando IR reactor cell and reaction conditions, the apparent cracking and dehydrogenation rates of propane obtained in 
such conditions were compared (i) to those obtained for H-MFI(29) in a conventional plug flow reactor operated at typical reaction temperatures, and (ii) to those reported in the literature for monomolecular cracking over H-MFI zeolites ${ }^{10,28-29}$. Figure 1 shows the Arrhenius plot of the corresponding rate constants normalized by the number of acidic $\mathrm{OH}$ groups of the zeolites.
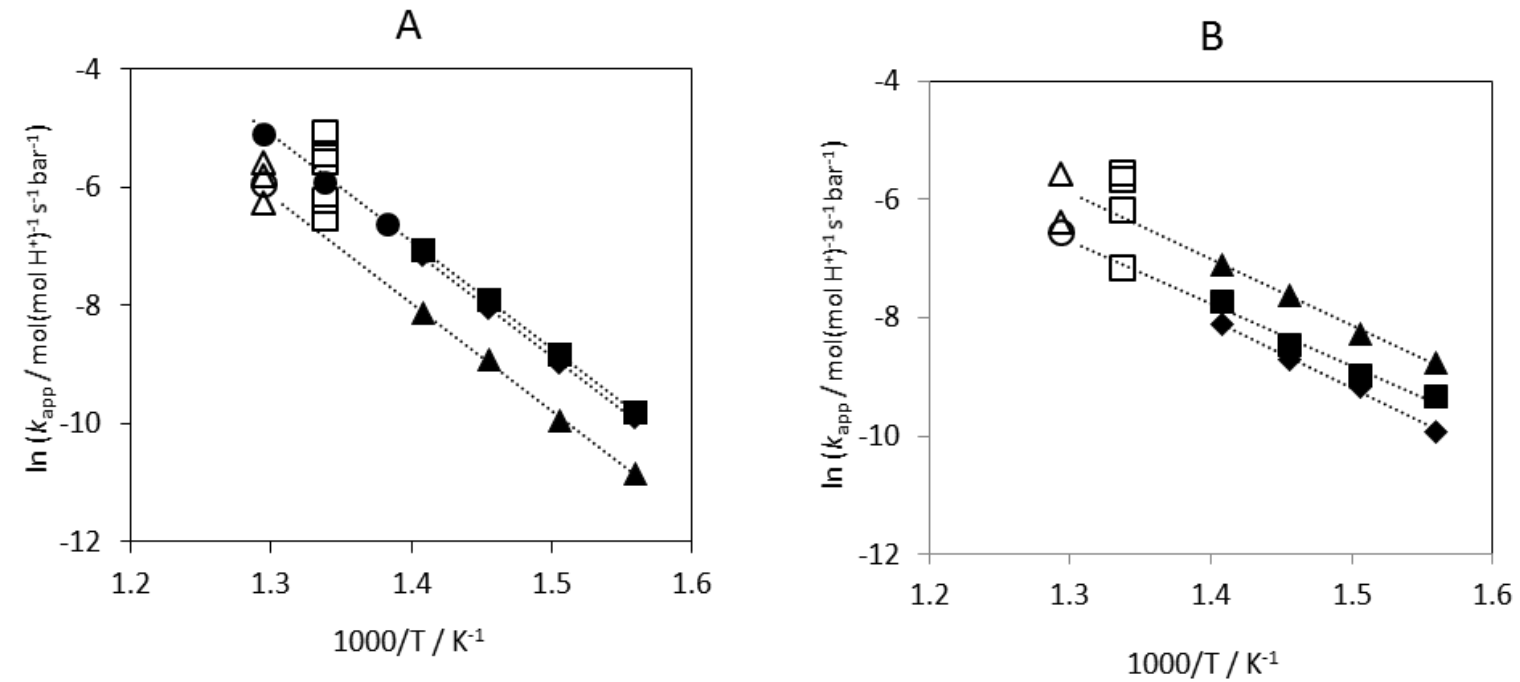

Figure 1. Arrhenius plots of propane monomolecular cracking (A) and dehydrogenation (B) turn-over frequencies over H-MFI zeolites: $(\bullet)$ H-MFI(29) in conventional reactor, (匹) HMFI(29) in IR operando cell, ( $)$ H-MFI(20) in IR operando cell, ( $\boldsymbol{\Delta}$ ) H-MFI(75) in IR operando cell, $(\Delta)$ Liu et al., $(\mathrm{Si} / \mathrm{Al}=43 \text { and } 71)^{29}(\circ)$ Narbeshuber et al.${ }^{10}(\mathrm{Si} / \mathrm{Al}=35)$ and $(\square)$ Gounder and $\operatorname{Iglesia}(\mathrm{Si} / \mathrm{Al}=16.2,16.5,19,25$ and 40$) .{ }^{28}$

The Arrhenius plots obtained for propane cracking over H-MFI(29) in both reactors matched satisfactorily and no significant effect of the reactor on either the slopes or the intercepts of the Arrhenius plots was found. This indicates that the rate measurements are not affected by the operando cell geometry, in agreement with recent studies in which direct comparisons between conventional reactor and operando transmission IR cells are reported. ${ }^{24,}{ }^{30}$ Hence, the apparent reaction parameters (pre-exponential factor and apparent energy of activation) obtained using the 
operando cell are comparable to those obtained using a conventional plug flow reactor.

Moreover, the extrapolation to higher temperatures of the rates determined in our conditions is also consistent with the apparent monomolecular cracking rates reported by other groups using conventional reactors. The apparent activation energies determined here $\left(150 \mathrm{~kJ} \mathrm{~mol}^{-1}\right.$ for the three zeolites investigated) is also very consistent with those reported previously. Interestingly, the variability of the apparent rates measured in our conditions over the three H-MFI samples (about a factor two between H-MFI(75) and H-MFI(29)) is also consistent with that reported in previous studies and is accounted by different distributions of $\mathrm{Al}$ atoms in the MFI structure (see refs. $^{21-22,29,31}$ and discussion below). In this respect, the reaction rates and rate parameters derived from our measurements are averaged over these distributions. Figure 1B shows a similar plot for dehydrogenation rates. For this reaction, significant differences were also found among the three zeolites in term of turnover frequencies. It is worth noticing that in our conditions the relative activities for dehydrogenation differed from those obtained for cracking: while $\mathrm{H}$ MFI(75) was the least active for cracking, it was the most active for dehydrogenation. The apparent activation energies for dehydrogenation were of the order of $90 \mathrm{~kJ} \mathrm{~mol}^{-1}$, close from the lowest values reported in the literature. ${ }^{10}$

\section{Assessment of the coverage of acid $\mathrm{OH}$ groups by the alkane reactant.}

H-MFI zeolites were chosen because they are extensively used to study the monomolecular cracking of alkanes in both experimental ${ }^{4,8-12,15-16}$ and theoretical ${ }^{17,20-21,32}$ studies. Besides, their acidic bridged $\mathrm{OH}$ groups lead to a single $\mathrm{vOH}$ band at $3600 \mathrm{~cm}^{-1}$ which, upon interaction with an alkane, form a hydrogen bond complex which results in a downward shift of the $\mathrm{vOH}$ band. ${ }^{6}$,

${ }^{33}$ This is illustrated in Figure 2a which shows the difference spectra (spectra at reaction conditions minus the spectrum of the zeolite before reaction) at constant temperature, and 
variable partial pressures and contact times for propane cracking over H-MFI(29) zeolite. In order to prevent experimental bias, the alkane partial pressures and contact times were changed in a non-monotonic order during the experiment.

(a)

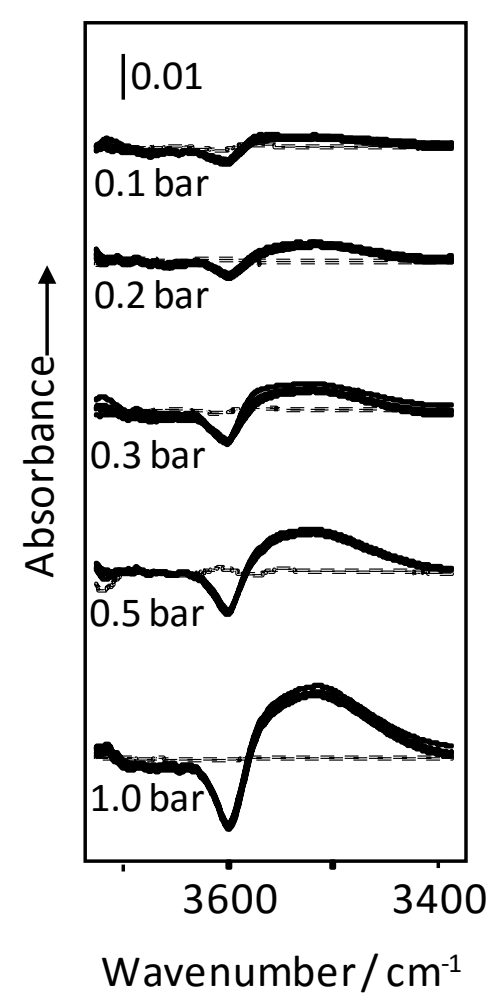

(b)
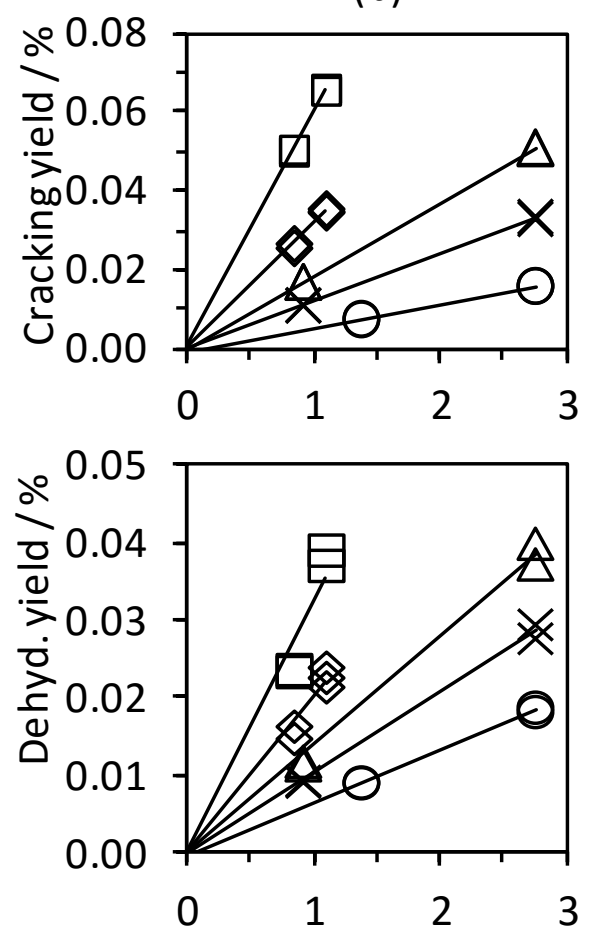

Contact time $/ 10^{4} \mathrm{~s} \mathrm{~g} \mathrm{~mol}^{-1}$

Figure 2. (a) Difference IR spectra in the $\mathrm{vOH}$ range of $\mathrm{H}-\mathrm{MFI}(29)$ at increasing partial pressure of propane at $698 \mathrm{~K}$. Dotted spectra were obtained after propane shut off. (b) Corresponding yields of cracking and dehydrogenation products vs. contact times $(\bigcirc 0.1 \mathrm{bar}, \times 0.2 \mathrm{bar}, \triangle 0.3 \mathrm{bar}, \diamond$ 0.5 bar, $\square 1.0$ bar). The pressure set points were fixed on a non-monotonic order.

The spectral features of the difference IR spectra shown in Figure 2a characterize the formation of hydrogen bonds between the $\mathrm{OH}$ groups of the zeolite with the reactant or products, leading to the negative $\mathrm{vOH}$ band at $3600 \mathrm{~cm}^{-1}$ and the broader positive $\mathrm{vOH}$ band at $\sim 3530 \mathrm{~cm}^{-}$ ${ }^{1.33-35}$ It is worth noting that at fixed temperature and pressure, no significant variation of 
intensity with contact time was observed. Examination of the characteristic bands of the adsorbed hydrocarbons, such as $v \mathrm{CH}, v \mathrm{CC}$ or $\delta \mathrm{CH}$ was generally not possible because of the strong contributions of the alkane in the gas phase in most of our conditions which made difficult the observation the vibration modes of the adsorbed molecules. When such observation was possible (at low temperature and partial pressure), the position of these bands did not differ significantly from the gas phase. This is expected under the conditions of monomolecular cracking, where it is expected that the adsorbed alkanes form weak hydrogen bonds with the acidic $\mathrm{OH}$ groups - as evidenced by the $\mathrm{vOH}$ spectrum above, or interact non-specifically with the zeolite walls or external surface (see also Supporting Information).

Figure $2 \mathrm{~b}$ shows the yields in cracking and dehydrogenation products (methane, ethylene and propene, respectively) obtained in these conditions. Both yields were found to increase linearly with the contact time as expected in differential conditions, while the amount of $\mathrm{OH}$ groups interacting with the reacted feed was nearly constant. Similar behavior was observed for all the alkanes and reaction temperatures investigated here. This indicates that the zeolite acid sites were not significantly affected by the adsorption of the reaction products, in particular alkenes, for which the concentrations are much lower than those of the alkane reactant in our conditions (by 2-3 orders of magnitude, see Figure 2b). These spectroscopic evidences are thus fully consistent with the usual assumption consisting in neglecting adsorption of products for the determination of the cracking rate constant in differential conditions (Eqn. 1 above). Finally, Figure 2a also shows that the initial $\mathrm{OH}$ spectrum of the bare zeolite was fully recovered after shutting off the alkane flow, as indicated by flat difference spectra (Figure 2a, dotted lines). This points out that no irreversible poisoning of the acid sites occurred during the reaction. The negative band at $3600 \mathrm{~cm}^{-1}$ could thus be used to determine the amount of reactant (alkane) in interaction with the 
zeolite acid sites $[\mathrm{ZOH} \cdots \mathrm{A}]$ using the absorption coefficient determined by pyridine dosing $(3.5$ $\left.\mathrm{cm} \mu \mathrm{mol}^{-1}\right)$.

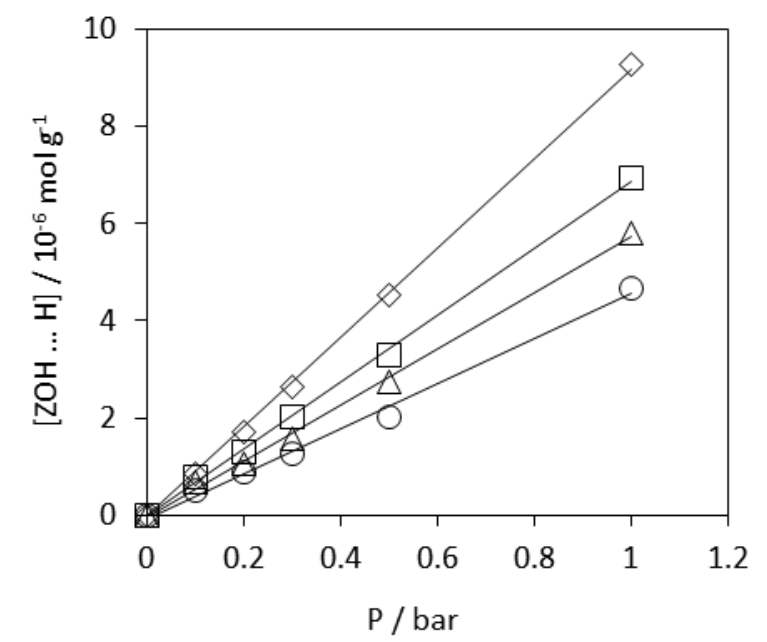

Figure 3. Propane adsorption isotherms over H-MFI(29) at reaction temperatures: $641 \mathrm{~K}(\diamond)$, $664 \mathrm{~K}(\square), 687 \mathrm{~K}(\Delta)$ and $710 \mathrm{~K}(\circ)$. The pressure set points were fixed on a non-monotonic order.

Figure 3 shows the adsorption isotherms thus obtained for propane adsorption over H-MFI(29) in the $640-710 \mathrm{~K}$ range. It shows that the coverage of acid sites increased linearly with the alkane pressure, indicating that within the pressure and temperature ranges reported here, propane adsorption obeyed Henry's law, as discussed earlier, in the conditions of monomolecular cracking (see Eqn. 3 above). Similar behaviors, albeit for smaller pressure ranges (see Supporting Information), were observed for the higher alkanes $\left(\mathrm{C}_{4}-\mathrm{C}_{7}\right)$.

Because the perturbation of the $\mathrm{OH}$ groups by the alkane was fully reversible, the adsorption constants at various temperatures $K_{\text {ads }}^{\circ}(T)$ could then be obtained from the slopes of the coverage of acidic OH groups vs. alkane partial pressure plots using (see also Eqn. 3 above):

$$
K_{\mathrm{ads}}^{\circ}(T)=\frac{d[\mathrm{ZOH} \cdots \mathrm{A}]}{d P} \frac{P^{\circ}}{L}
$$


where $L$ is the total concentration of acidic $\mathrm{OH}$ groups of the zeolite and $P^{\circ}$ is the pressure of the standard state $(1$ bar). With such a definition, the coverage of the standard state of the adsorbed alkane and of the free acid sites is $\theta_{A}{ }^{\circ}=0.5 .^{36}$

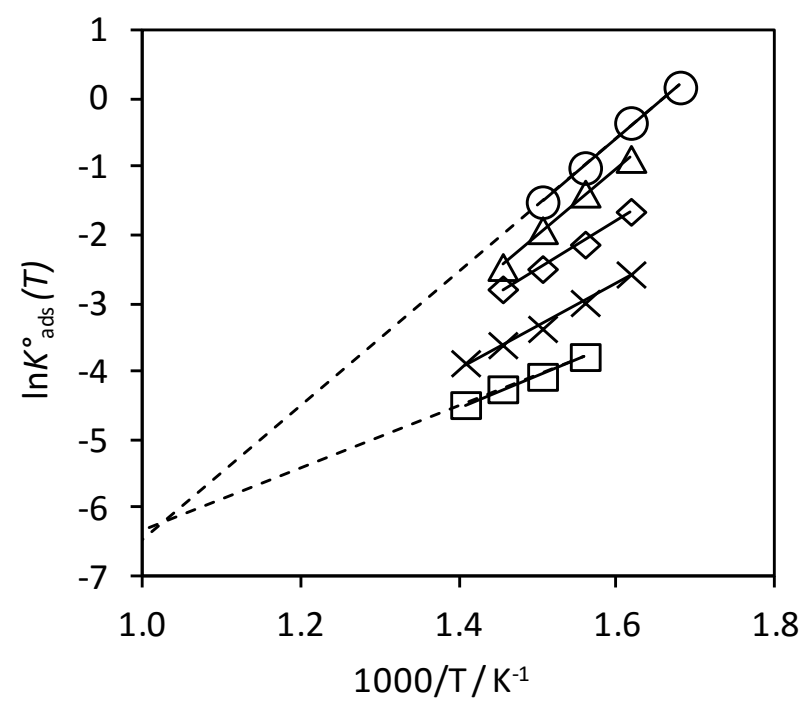

Figure 4. van't Hoff plots of alkanes adsorption constants over H-MFI(29) acid sites: propane $(\square)$, butane $(\times)$, pentane $(\diamond)$, hexane $(\Delta)$ and heptane $(\circ)$.

Figure 4 shows the van't Hoff plots of the adsorption constants obtained for $\mathrm{C}_{3}-\mathrm{C}_{7}$ adsorption over zeolite $\mathrm{H}-\mathrm{MFI}(29)$. The corresponding adsorption thermodynamic parameters $\Delta_{\text {ads }} H$ and $\Delta_{\mathrm{ads}} S$ were then obtained from the slope and the intercept of these van't Hoff plots. The corresponding values, together with those previously reported from low temperature measurements, ${ }^{6-7,10}$ or theoretical studies ${ }^{20}$ are reported in Tables 1 and 2 for enthalpies and entropies, respectively. Figure 4 shows that while the coverage of active sites increases with the alkane size at low temperature, the differences tend to decrease at higher temperature because of enthalpy - entropy compensation effects (Table 1 and 2) ${ }^{8,12}$ Extrapolation to higher temperatures indicates that the adsorption constants of propane and n-heptane tend to equalize at 
$\sim 825 \mathrm{~K}$, supporting the initial hypothesis of Bhan et al. ${ }^{9}$ based on much lower temperature measurements. ${ }^{6}$

Table 1. Comparison of standard adsorption enthalpies with previous experimental and theoretical studies. Values are given in $\mathrm{kJ} \mathrm{mol}^{-1} \mathrm{~K}^{-1}$

\begin{tabular}{|c|c|c|c|c|c|c|c|c|c|}
\hline \multirow{2}{*}{\multicolumn{2}{|c|}{ Alkane Si/Al }} & \multicolumn{4}{|c|}{ Experimental determinations } & \multicolumn{4}{|c|}{ Theoretical determinations } \\
\hline & & $\begin{array}{l}\text { This } \\
\text { work. }{ }^{a}\end{array}$ & $\begin{array}{c}\text { Narbesh- } \\
\text {-uber et } \\
\text { al. }^{b}\end{array}$ & $\begin{array}{l}\text { Eder et } \\
\text { al. }{ }^{6-7 b}\end{array}$ & $\begin{array}{l}\text { De Moor } \\
\text { et al. }{ }^{17 c}\end{array}$ & $\begin{array}{c}\text { De Moor et } \\
\text { al. } .^{d}\end{array}$ & $\begin{array}{l}\text { Swish } \\
\text { er et } \\
\text { al. }{ }^{37}\end{array}$ & $\begin{array}{l}\text { Tranca } \\
\text { et al. }{ }^{20, e}\end{array}$ & $\begin{array}{c}\text { Janda et } \\
\text { al. }^{21, e, f} f\end{array}$ \\
\hline \multirow{3}{*}{$\mathrm{C}_{3}$} & 20 & $-39(2)$ & \multirow{3}{*}{-43} & \multirow{3}{*}{-45} & \multirow{3}{*}{-41} & \multirow{3}{*}{$-52 /-64$} & \multirow{3}{*}{-38} & \multirow{3}{*}{-37} & \multirow{3}{*}{-44} \\
\hline & 29 & $-38(2)$ & & & & & & & \\
\hline & 75 & $-42(2)$ & & & & & & & \\
\hline \multirow[t]{2}{*}{$\mathrm{C}_{4}$} & 29 & $-51(4)$ & \multirow[t]{2}{*}{-62} & \multirow[t]{2}{*}{-58} & \multirow[t]{2}{*}{-52} & \multirow[t]{2}{*}{$-68 /-78$} & \multirow[t]{2}{*}{-46} & \multirow[t]{2}{*}{-52} & \multirow[t]{2}{*}{-53} \\
\hline & 20 & $-65(4)$ & & & & & & & \\
\hline \multirow[t]{2}{*}{$\mathrm{C}_{5}$} & 29 & $-65(2)$ & \multirow[t]{2}{*}{-74} & \multirow[t]{2}{*}{-69} & \multirow[t]{2}{*}{-62.5} & \multirow[t]{2}{*}{$-85 /-92$} & \multirow[t]{2}{*}{-55} & \multirow[t]{2}{*}{-67} & \multirow[t]{2}{*}{-63} \\
\hline & 75 & $-65(1)$ & & & & & & & \\
\hline \multirow{3}{*}{$\mathrm{C}_{6}$} & 20 & $-85(4)$ & \multirow{6}{*}{-92} & \multirow{6}{*}{-83} & \multirow{6}{*}{-72} & \multirow{6}{*}{$-101 /-106$} & \multirow{6}{*}{-64} & \multirow{6}{*}{-81} & \multirow{3}{*}{-73} \\
\hline & 29 & $-81(3)$ & & & & & & & \\
\hline & 75 & $-85(3)$ & & & & & & & \\
\hline \multirow{3}{*}{$\mathrm{C}_{7}$} & 20 & $-100(3)$ & & & & & & & \\
\hline & 29 & $-106(4)$ & & & & & & & \\
\hline & 75 & $-106(2)$ & & & & & & & \\
\hline
\end{tabular}

${ }^{a}$ Obtained at $600-700 \mathrm{~K}$, standard errors are in parentheses. ${ }^{b}$ obtained experimentally at $320 \mathrm{~K}$. ${ }^{c}$ Obtained at 300-400 K. ${ }^{d}$ obtained by ab initio QM-Pot(MP2//B3LYP) static simulations at $0 \mathrm{~K}$ and standard statistical thermodynamics calculations at $773 \mathrm{~K}$. The two values correspond to adsorption in straight and zig-zag channels, respectively. ${ }^{e f f}$ Conformational Bias Monte carlo simulations (CBMC) 773 K. ${ }^{g} \mathrm{CBMC}, 773 \mathrm{~K}$. 
Table 2. Comparison of standard adsorption entropies with previous experimental and theoretical studies. Values are given in $\mathrm{J} \mathrm{mol}^{-1} \mathrm{~K}^{-1}$

\begin{tabular}{|c|c|c|c|c|c|c|c|c|}
\hline \multirow[b]{2}{*}{ Alkane } & \multirow[b]{2}{*}{$\mathrm{Si} / \mathrm{Al}$} & \multicolumn{3}{|c|}{ Experimental determinations } & \multicolumn{4}{|c|}{ Theoretical determinations } \\
\hline & & This work. $^{a}$ & $\begin{array}{l}\text { Eder et } \\
\text { al. }^{6-7, b}\end{array}$ & $\begin{array}{c}\text { De Moor et } \\
\text { al. }^{17 c}\end{array}$ & $\begin{array}{c}\text { De Moor et } \\
\text { al. }{ }^{17, d}\end{array}$ & $\begin{array}{c}\text { Swishe } \\
\text { r et } \\
\text { al. }^{37, e}\end{array}$ & $\begin{array}{c}\text { Tranca et } \\
\text { al. }{ }^{20, e}\end{array}$ & $\begin{array}{c}\text { Janda et } \\
\text { al. }^{21, f}\end{array}$ \\
\hline & 20 & $-89(4)$ & & & & & & \\
\hline $\mathrm{C}_{3}$ & $\begin{array}{l}29 \\
75\end{array}$ & $\begin{array}{l}-91(3) \\
-95(3)\end{array}$ & -102 & -94 & $-96 /-96$ & -39 & -39 & -104 \\
\hline $\mathrm{C}_{4}$ & 29 & $-105(5)$ & -119 & -104 & $-102 /-105$ & -48 & -48 & -114 \\
\hline & 20 & $-118(6)$ & & & & & & \\
\hline $\mathrm{C}_{5}$ & 29 & $-119(3)$ & -135 & -118 & $-108 /-114$ & -58 & -60 & -123 \\
\hline & 75 & $-120(1)$ & & & & & & \\
\hline & 20 & $-145(6)$ & & & & & & \\
\hline $\mathrm{C}_{6}$ & 29 & $-138(4)$ & -152 & -121 & $-113 /-122$ & -73 & -70 & -133 \\
\hline & 75 & $-146(4)$ & & & & & & \\
\hline & 20 & $-161(4)$ & & & & & & \\
\hline $\mathrm{C}_{7}$ & 29 & $-174(7)$ & & & & & & \\
\hline & 75 & $-169(4)$ & & & & & & \\
\hline
\end{tabular}

${ }^{a}$ Obtained at $600-700 \mathrm{~K}$, standard errors are in parentheses. ${ }^{b}$ obtained experimentally at $320 \mathrm{~K}$. ${ }^{\mathrm{c}}$ Obtained at 300-400 K. ${ }^{d}$ obtained by ab initio QM-Pot(MP2//B3LYP) static simulations at $0 \mathrm{~K}$ and standard statistical thermodynamics calculations at $773 \mathrm{~K}$. The two values correspond to adsorption in straight and zig-zag channels, respectively. ${ }^{e}$ Conformational Bias Monte Carlo simulations (CBMC) $773 \mathrm{~K}$. ${ }^{g} \mathrm{CBMC}, 773 \mathrm{~K}$, values corrected for the standard state $\theta_{A}{ }^{\circ}=0.5$. 
Tables 1 and 2 also show that our estimates of adsorption enthalpies and entropies are consistent with earlier experimental determination. It is worth noting however that the magnitudes of adsorption entropies are slightly, but systematically lower than those reported by Eder and al. by $\sim 10 \mathrm{~J} \mathrm{~mol}^{-1} \mathrm{~K}^{-1}$ and close from those reported by De Moor et al. Comparison of these experimental values with those predicted by molecular simulations show a generally fair agreement for adsorption enthalpies while the simulation methodology has a large impact on the predicted entropies. The values reported by De Moor et al. ${ }^{17}$ were obtained by static DFT calculations at $0 \mathrm{~K}$ with a correction for long range interactions followed by standard statistical thermodynamic calculations at $773 \mathrm{~K}$. The predicted adsorption enthalpies are significantly more negative than the experimental values (by $10-20 \mathrm{~J} \mathrm{~mol}^{-1} \mathrm{~K}^{-1}$ ), while the reported adsorption entropies showed a fairly good agreement with the experimentally determined values. By contrast, the magnitudes of adsorption entropies reported by Swisher et al. ${ }^{37}$ and Tranca et al. ${ }^{20}$ are nearly two times lower than those experimentally determined. While both authors have compared their values with experiments, it should be noted that such a comparison is not straightforward because of differences in (i) the reference states and (ii) the configuration space used to compute the adsorption entropies.

The comparison of adsorption entropies from various sources (experimental or simulation studies) must take into account the reference states of the gas phase, of the adsorption sites, and of the adsorbed phase. Considering the adsorption process of an alkane in the gas phase: $A_{g}+* \rightarrow A^{*}$, the corresponding standard adsorption entropy is defined as:

$$
\Delta_{a d s} S^{\circ}=S^{\circ}(A *)-S^{\circ}\left(A_{g}\right)-S^{\circ}(*)
$$


In experimental measurements, the standard state for the gas phase is generally taken at $P^{\circ}=1$ bar, but there is no generally accepted standard states for adsorbates. Because the thermodynamic activities of adsorption sites and of adsorbed species are primarily governed by their coverage $\theta$, the corresponding standard states must be taken at given coverages $\theta_{A *}^{\circ}$ and $\theta_{*}^{\circ}$. While any standard coverage can be used (see Eqns. 3 and 8 above), recent studies and recommendations in the field use standard states for the adsorbate and the adsorption site taken at $\theta_{A *}^{\circ}=\theta_{*}^{\circ}=0.5 \cdot{ }^{6-7,17,36}$ With such a choice, the configurational entropies of the adsorbed phase and of the free surface cancel each other. This choice also naturally arises when the entropies are derived from the van't Hoff plots of Langmuir or Henry adsorption constants as considered in this work. However, the Monte Carlo simulations carried out by Swisher et al. and Tranca et al. have considered the adsorption of a single molecule in the simulation box representing the zeolite from the gas phase in its standard state ( 1 bar). Therefore, the adsorption entropy must be corrected for the reference state of the adsorbed phase. Assuming that the differences of entropy due to change of coverage are mostly due to the configurational entropy, the values reported by Swisher et al. and Tranca et al. thus differ from the standard adsorption entropy according to:

$$
\Delta_{a d s} S=\Delta_{a d s} S^{\circ}+S_{\text {config }}(A *)
$$

where, $S_{\text {config }}(A *)$ is the configurational entropy of one alkane molecule adsorbed in the simulation box. This additional term, difficult to assess without further simulations, explains in part why the adsorption entropies reported by these studies exceed by far the standard adsorption entropies reported here.

A second source of discrepancy, which was identified by Tranca et al., arises from different definitions of the adsorbed state, which in turn defines the configuration space used to determine 
its entropy. Our estimates are based on the spectroscopic observation of the hydrogen bond between the acid site and the reactant while simulations of Tranca et al. and Swisher et al. consider larger configuration spaces where all adsorbed states of the alkane are taken into account, including those where it does not interact with the acid site. As shown by the quantum molecular dynamic studies of Bučko et al. ${ }^{18}$ and Jiang et al.,${ }^{19}$ the hydrogen bonding interaction dominates at low temperature and alkanes form stable adsorption complexes with the acid sites. However, the probability of forming hydrogen bonded states decreases with temperature and becomes much lower at temperatures typical of the reaction where most of the alkanes are at distances too large to form hydrogen bonds. ${ }^{18}$ Hence, when all adsorbed states are taken into account, the configuration space of the adsorbed phase expands with temperature, leading to higher entropy. This gives smaller magnitudes of adsorption entropies as compared to the values determined in the present study where the configuration space is limited to hydrogen bonded states. By contrast with the definition of the standard state discussed above, the choice of the configuration space has fundamental consequences because it merely defines the initial reactant state of the cracking reaction. In the present case, molecular simulations lump adsorption states that are usually considered distinct and consecutive: adsorption in the zeolite pores by van der Waals interactions, followed adsorption on the active site (see e.g. Scheme 2 in ref. ${ }^{9}$, or Figure 1 in ref. ${ }^{20}$ ). These states are energetically distinct because the hydrogen bonded state gives a stabilization of $\sim 10 \mathrm{~kJ} \mathrm{~mol}^{-1}{ }^{6}$ At low temperatures, this distinction does not import much because most of the alkanes are localized on the acid site. ${ }^{6}$ This explains why the adsorption parameters predicted by De Moor et al., ${ }^{17}$ who have considered only the hydrogen-bonded state in its configuration at $0 \mathrm{~K}$, or by the Monte Carlo simulations of Tranca et al. ${ }^{20}$ at room temperature are close to the experimental ones. 
Finally, in two recent studies, Janda et al..$^{21-22}$ have improved the approach used by Swisher et al. and Tranca et al. by restricting the configuration space to adsorbed species at the vicinity of the active sites, by defining a cut-off radius of $5 \AA$ around the $\mathrm{Al}$ atom, i.e. in regions where the formation of a hydrogen bonded complexes has a high probability. As shown in Tables 1 and 2, this modified approach leads to similar adsorption enthalpies and to a much better agreement for the adsorption entropies. As will be discussed below, however, this new approach does not completely solve the discrepancy on activation parameters derived from experiments and simulations.

\section{Assessment of apparent and intrinsic monomolecular cracking and dehydrogenation rates}

In order to determine the intrinsic cracking rate parameters, the apparent cracking rates were measured simultaneously with the concentration of the acid site - alkane hydrogen bond complexes $[\mathrm{ZOH} \cdots \mathrm{A}]$, which are considered as the initial states for the monomolecular cracking reaction. Figure 5 shows the evolution of these apparent cracking rates versus $[\mathrm{ZOH} \cdots \mathrm{A}]$ at various temperatures and pressures of the alkanes investigated in this study. It indicates a very good correlation between apparent rates $r$ and the concentration of hydrogen bonded alkanes $[\mathrm{ZOH} \cdots \mathrm{A}]$ (alkane coverage). The intrinsic rate constants $k_{\mathrm{int}}(\mathrm{T})$ are given by the slopes of these correlations. 

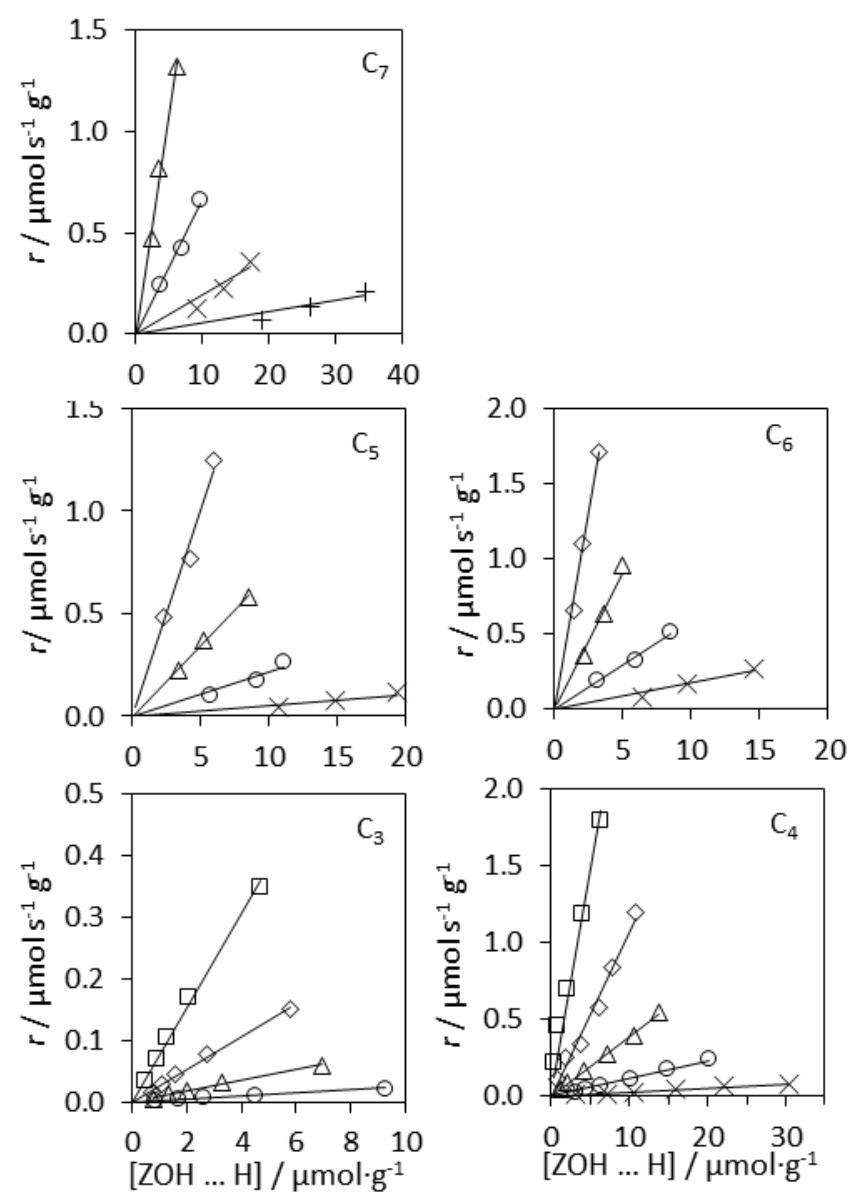

Figure 5. Correlation between alkane apparent cracking rates and the corresponding concentration of acid site - alkane hydrogen complexes $[\mathrm{ZOH} \cdots \mathrm{A}]$, at various pressures and temperatures: 710K $(\square), 687 \mathrm{~K}(\diamond), 664 \mathrm{~K}(\Delta), 641 \mathrm{~K}(\circ), 618 \mathrm{~K}(\times)$ and 595K $(+)$.

Figure $6 \mathrm{a}$ and Figure $6 \mathrm{~b}$ show the Arrhenius plots of the apparent cracking rate constants normalized to the number of $\mathrm{OH}$ acid sites (or turnover frequencies), and the intrinsic rate constants of propane monomolecular cracking over the three zeolites investigated in the present study. The intrinsic activation energies were found nearly identical for the three zeolites: 192(3), 189(4) and 189(2) $\mathrm{kJ} \mathrm{mol}^{-1}$ for $\mathrm{H}-\mathrm{MFI}(29), \mathrm{H}-\mathrm{MFI}(20)$ and $\mathrm{H}-\mathrm{MFI}(75)$, respectively. These values are consistent with those previously derived from the use of low temperature adsorption for propane cracking data over H-MFI zeolites $\left(187-205 \mathrm{~kJ} \mathrm{~mol}^{-1}\right),{ }^{9-10,20}$ yet lying in the lower range of these 
values. It is worth noting that the Arrhenius plots of the three zeolites show very similar shift along the ordinate axis for both apparent and intrinsic rate constants (Figure 6a and Figure 6b, respectively), indicating that the differences in apparent cracking activity per active site are essentially due to changes in the intrinsic rate constants. Hence, the pre-exponential factor was significantly lower for H-MFI(75), while zeolite H-MFI(20) and H-MFI(29) could not be distinguished in terms of cracking activity. This trend, where the zeolite having the lowest $\mathrm{Al}$ content has the lowest cracking turnover frequency, is in agreement with the study of Janda and $\mathrm{Bell}^{38}$, who have evidenced a similar decrease with $\mathrm{Si} / \mathrm{Al}$ ratio for butane cracking. In particular, they have been able to relate this trend to the increase of the fraction of acid sites located in the intersection of the channels relative to that of acid sites located in the channels. However, it is worth mentioning that studies by Gounder and Iglesia ${ }^{28}$ or Liu et al. ${ }^{29}$ show that in absence of indication as to the location of acid sites, no such a correlation between $\mathrm{Si} / \mathrm{Al}$ ratio and turnover frequencies can generally be made, including for zeolites from the same provider for which the cracking (and dehydrogenation) rates are not correlated to the framework Al content or to the amount of Brønsted or Lewis acid sites. ${ }^{28}$ Because of the limited number of zeolites investigated here and the lack of information on the distribution of their acid sites, the origin of the differences in intrinsic cracking activity of these zeolites cannot be commented further. 

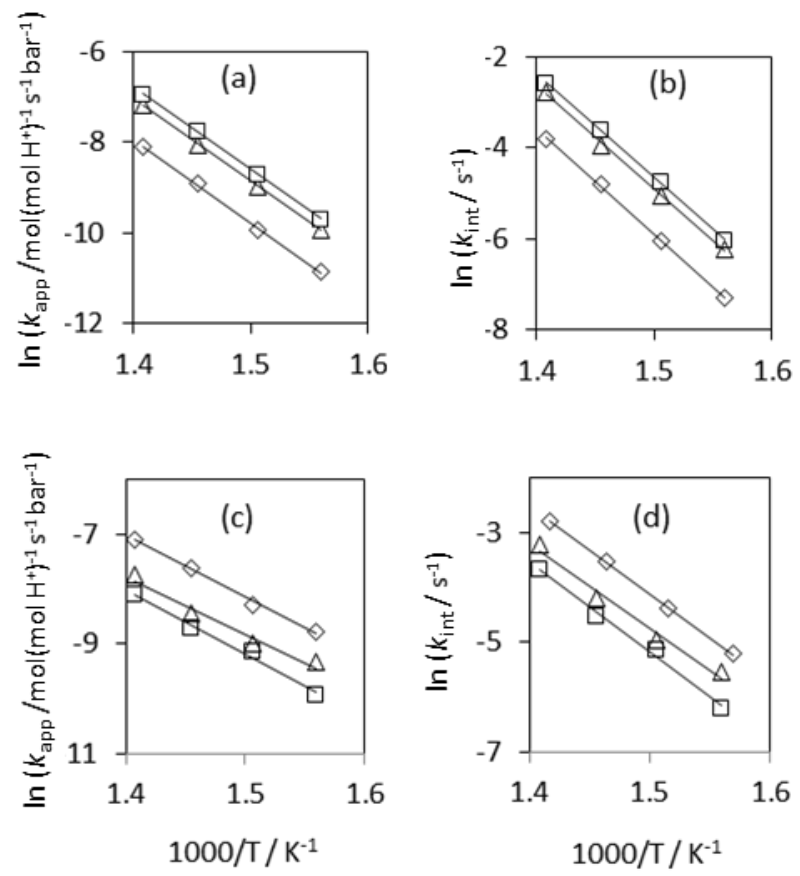

Figure 6. Arrhenius plots of (a) apparent cracking rates, (b) intrinsic cracking rate constants, (c) apparent dehydrogenation rates and (d) intrinsic dehydrogenation rate constants for propane over H-MFI zeolites with different Si/Al ratio: ( $\Delta$ ) H-MFI(20), ( $\square)$ H-MFI(29) and (৩) H$\operatorname{MFI}(75)$.

The Arrhenius plots showing the temperature dependence of apparent and intrinsic dehydrogenation rate constants for cracking and dehydrogenation are exhibited on Figure $6 \mathrm{c}$ and 6d, respectively. Like for the cracking reaction (Figures $6 \mathrm{a}$ and $6 \mathrm{~b}$ ), the ranking of apparent rates follows that of intrinsic rates. The apparent activation energies were of the order of $90 \mathrm{~kJ} \mathrm{~mol}^{-1}$ for the three zeolites: 87(11), 89(10) and 93(5) $\mathrm{kJ} \mathrm{mol}^{-1}$ for H-MFI(29), H-MFI(20) and H$\operatorname{MFI}(75)$, a value close from that reported by Narbeshuber et al. $\left(96 \mathrm{~kJ} \mathrm{~mol}^{-1}\right)$, but much lower than the values of $\sim 200 \mathrm{~kJ} \mathrm{~mol}^{-1}$ reported by Gounder and Iglesia ${ }^{7}$ or Liu et al. ${ }^{29}$ Table 3 below compares the apparent activation energies and activation entropies (Eqns. 6-8) for dehydrogenation of propane, butane and pentane on H-MFI(29) with typical values reported in 
the literature (the apparent activation entropies were computed from the reported data and use of Eqns. 6-8). The dehydrogenation rates for higher alkanes (hexane and heptane) could not be obtained with enough precision due to secondary cracking of the dehydrogenated products.

Our data show that the increase of the alkane chain length, from $\mathrm{C}_{3}$ to $\mathrm{C}_{5}$, lead to an increase of apparent activation energies and a decrease of the magnitude of activation entropies, in agreement with the results reported by Narbeshuber et al.${ }^{10}$ More strikingly, as already reported by others, the values of apparent rate parameters reported in the literature show a large dispersion, for both apparent activation energies (from $\sim 100$ to $\sim 200 \mathrm{~kJ} \mathrm{~mol}^{-1}$ ) and apparent activation entropies (from -150 to $-11 \mathrm{~J} \mathrm{~mol}^{-1} \mathrm{~K}^{-1}$ ). The values reported here belong to the set of apparent rate constants with low activation energies/very negative activation entropies, such as those reported by Narbeshuber et al. ${ }^{10}$ To our knowledge, only Janda and Bell have proposed a rationale for this dispersion. ${ }^{38}$ In the case of butane, they have shown that dehydrogenation apparent rates were strongly affected by isobutene which specifically inhibits dehydrogenation active sites. A major consequence of this inhibition, which violates the assumption that adsorption of products can be neglected in the calculation of rate constants (Eqns. 2-3), is that the values of turnover frequencies are affected by the contact time, whereby longer contact times lead to larger inhibition and lower turnover frequencies. Hence, Janda and Bell have recommended to use turnover frequencies extrapolated at zero contact time for the determination of the dehydrogenation rate parameters. They have shown that in their conditions, this led to increased values of apparent activation energies. ${ }^{38}$ As shown in the Supporting Information, we have also observed a similar influence of the contact time on butane dehydrogenation turnover frequencies, confirming the inhibition of dehydrogenation sites by reaction products. However, such a phenomenon was not observed for propane dehydrogenation and more importantly, we 
did not observe a significant change of the perturbation of the $\mathrm{OH}$ groups with contact time at fixed pressure and temperature for either propane (as shown in Figure 2, above) or butane (Supporting information). As discussed above, this is spectroscopic evidence that in our conditions the zeolite acidic $\mathrm{OH}$ groups were not affected by the increased yield of reaction products. Hence, the change of dehydrogenation turnover frequencies at constant coverage of $\mathrm{OH}$ groups is an indication that either a minority of undetected acidic $\mathrm{OH}$ groups are responsible for a significant part the dehydrogenation activity or that other types of sites act as dehydrogenation centers. In particular, it is well known that Lewis acid sites of zeolites are very active for dehydrogenation reactions with low activation barriers. ${ }^{28,39-40}$ Although the zeolite having the largest dehydrogenation activity did not present an appreciable amount of Lewis acid sites (Supporting Information), it is likely that a minority of defect sites, in the zeolite pores or at its external surface act as dehydrogenation centers. It is worth noticing that Janda and Bell did observe a fast initial deactivation of butane dehydrogenation centers while the cracking activity was much more stable and proposed that the initial dehydrogenation they observed originated from Lewis acid sites. It is thus possible that in our conditions (in particular lower temperature), no significant deactivation of such sites occurs, although small activation energies for dehydrogenation, presumably associated to Lewis acid sites, ${ }^{39-40}$ have also been reported for higher reaction temperatures (Table 3). In any case, since a significant fraction of dehydrogenation acitivity is not due to the acidic $\mathrm{OH}$ groups, the derivation of apparent turnover frequencies and intrisic dehydrogenation rates (as shown if Figures 6c and 6d) does not have much physical meaning, except for the assessment of apparent activation energy. In particular, such derivation lead to very negative, unrealistic intrinsic activation entropies (-80 and $-75 \mathrm{~J} \mathrm{~mol}^{-}$ ${ }^{1} \mathrm{~K}^{-1}$ for propane and butane, respectively). Such very negative values suggest that the number of 
dehydrogenation sites is much lower that of acidic $\mathrm{OH}$ groups. A proper derivation of relevant protolytic dehydrogenation rate parameters would require (i) ascertaining that all dehydrogenation sites other than zeolite $\mathrm{OH}$ groups are deactivated, and (ii) properly account for the correct fraction of acidic $\mathrm{OH}$ groups active in dehydrogenation. Indeed, in the hypothesis were only acid $\mathrm{OH}$ groups are active for this reaction, the sensitivity of the dehydrogenation turnover frequency to the contact time while cracking is not affected, indicates that this reaction occurs in distinct sites which have not yet been quantified to our knowledge, while previous studies have generally considered the whole population of $\mathrm{OH}$ groups for intrinsic entropy calculations. If such an approach may be useful on deriving systematic trends, we suggest here that caution should be taken when discussing their absolute values. In the present case, none of the two requirements are fulfilled and the proper dertermination of intrinsic dehydrogenation parameters is beyond the scope of the present work which focuses on the protolytic cracking of carbon-carbon bonds of light alkanes.

Table 3. Comparison of apparent dehydrogenation rate parameters on H-MFI(29) with previous experimental and studies. ${ }^{a}$

\begin{tabular}{|c|c|c|c|c|c|c|c|c|c|c|c|c|}
\hline \multirow{2}{*}{ 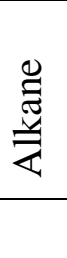 } & \multicolumn{2}{|c|}{ This work ${ }^{b}$} & \multicolumn{2}{|c|}{$\begin{array}{c}\text { Narbeshuber } \\
\text { et al. }{ }^{10, c}\end{array}$} & \multicolumn{2}{|c|}{$\begin{array}{l}\text { Krannila et } \\
\text { al. }^{41, d}\end{array}$} & \multicolumn{2}{|c|}{$\begin{array}{l}\text { Lercher et } \\
\text { al. }^{42, e}\end{array}$} & \multicolumn{2}{|c|}{$\begin{array}{l}\text { Gounder } \\
\text { and } \\
\text { Iglesia }^{28, f}\end{array}$} & \multicolumn{2}{|c|}{$\begin{array}{l}\text { Janda and } \\
\text { Bell }^{38, g}\end{array}$} \\
\hline & $E_{a p p}$ & $\Delta S_{a p p}$ & $E_{a p p}$ & $\Delta S_{a p p}$ & $E_{a p p}$ & $\Delta S_{a p p}$ & $E_{a p p}$ & $\Delta S_{a p p}$ & $E_{a p p}$ & $\Delta S_{a p p}$ & $E_{a p p}$ & $\Delta S_{a p p}$ \\
\hline $\mathrm{C} 3$ & 89 & -190 & 95 & -193 & & & & & 200 & -45 & & \\
\hline $\mathrm{C} 4$ & 102 & -144 & 115 & -154 & 149 & -120 & 105 & -150 & & & 208 & -11 \\
\hline $\mathrm{C} 5$ & 139 & -101 & & & & & & & & & & \\
\hline
\end{tabular}

${ }^{a}$ Activation energies in $\mathrm{kJ} \mathrm{mol}^{-1}$, entropies in $\mathrm{J} \mathrm{mol}^{-1} \mathrm{~K}^{-1} \cdot{ }^{b} \mathrm{H}-\mathrm{MFI}(29), 640-710 \mathrm{~K} ;{ }^{c} \mathrm{Si} / \mathrm{Al}=35$, $723-823 \mathrm{~K} ;{ }^{d} \mathrm{Si} / \mathrm{Al}=35,700-800 \mathrm{~K} ;{ }^{e} \mathrm{Si} / \mathrm{Al}=35,735-835 \mathrm{~K} ;{ }^{f} \mathrm{Si} / \mathrm{Al}=25,718-778 \mathrm{~K} ;{ }^{\mathrm{g}} \mathrm{Si} / \mathrm{Al}=$ $25,723-788 \mathrm{~K}$. 
By contrast with dehydrogenation, the changes of the $v(\mathrm{OH})$ band intensity with respect to all reaction conditions (partial pressure, temperature and contact time) respect all assumptions made to derive kinetic parameters for the protolytic cracking of carbon-carbon bonds. Hence, the usual assumption that all acidic $\mathrm{OH}$ groups of the zeolite are active for cracking is confirmed by the present results, even though the dependence of intrinsic rate constants on the zeolite sample indicates an influence of the location of the $\mathrm{OH}$ groups in the zeolite pores (Figure 6b), which primarily affects the pre-exponential factor $A$ of the intrinsic rate constant. The latter is related to the intrinsic activation entropy $\Delta S^{\ddagger}$ by the standard transition state theory formula $A=$ $v \exp \left(\Delta S^{\ddagger} / R\right)$ where $v=k_{B} T e / h$.

In order to compare with experimental studies ${ }^{9}$ the intrinsic activation entropy values can be corrected for the number of $\mathrm{C}-\mathrm{C}$ bonds of the alkane as follows: considering the global cracking rate constant $k_{\text {int }}=\sum_{i}^{n-2} k_{i}$ where $n$ is the alkane chain length and $k_{i}$ are the intrinsic rate constants for individual cracking reactions, the intrinsic cracking rate per $\mathrm{C}-\mathrm{C}$ bond is defined as $\left\langle k_{\text {int }}\right\rangle=k_{\text {int }} /(n-1)$, and the corresponding pre-exponential factor and activation entropy are defined as $\langle A\rangle=A /(n-1)$ and $\left\langle\Delta S^{\ddagger}\right\rangle=R(\ln \langle A\rangle-\ln v)$. With this definition, the carboncarbon bond corrected activation entropy $\left\langle\Delta S^{\ddagger}\right\rangle$ is related to the overall activation entropy $\left(\Delta S^{\ddagger}\right.$, Eqn. 5 and 8) by: $\left\langle\Delta S^{\ddagger}\right\rangle=\Delta S^{\ddagger}-R \ln (n-1)$. It is worthwhile noting that these activation entropies are not proportional to the mean of activation entropies of individual cracking reactions $\Delta S_{i}^{\ddagger}$ but are related to the log-sum of their exponentials:

$$
\Delta S^{\ddagger}=R \ln \sum_{i=1}^{n-2} \exp \left(\frac{\Delta S_{i}^{\ddagger}}{R}\right)
$$




$$
\left\langle\Delta S^{\ddagger}\right\rangle=R \ln \sum_{i=1}^{n-2} \frac{1}{n-1} \exp \left(\frac{\Delta S_{i}^{\ddagger}}{\mathrm{R}}\right)
$$

Because of these relationships both $\Delta S^{\ddagger}$ and $\left\langle\Delta S^{\ddagger}\right\rangle$ are dominated by the largest values of $\Delta S_{i}^{\ddagger}$. Table 4 summarizes the intrinsic cracking parameters (activation energies and entropies) determined in this work and shows a comparison with those reported by previous experimental and theoretical studies. As shown above (Figure 1 and $6 a$ ), the largest difference in the apparent turnover frequencies of propane cracking for the zeolites was observed to be on the order of a factor 2 for $\mathrm{H}-\mathrm{MFI}(29)$ compared to the higher Si/Al ratio zeolite H-MFI(75). Assuming rigorously identical adsorption parameters and intrinsic activation energies for propane cracking, this difference can be accounted for by differences in the activation entropies of $R \ln 2=5.7$ $\mathrm{J} \mathrm{mol}^{-1} \mathrm{~K}^{1}$. This difference compares favorably with the difference of the activation entropies determined from extrapolation of the Arrhenius plot: $\left\langle\Delta S^{\ddagger}\right\rangle=-21(4)$ and $-26(5) \mathrm{J} \mathrm{mol}^{-1} \mathrm{~K}^{-1}$ for $\mathrm{H}-$ $\operatorname{MFI}(29)$ and $\mathrm{H}-\operatorname{MFI}(75)$, respectively. It is worth nothing however that such differences are at the limit of the accuracy currently achieved for the determination intrinsic activation entropy (See e.g. ref. ${ }^{28}$ ).

Table 4 shows that the intrinsic activation energies are similar for all the alkanes investigated in this study $\left(\sim 190 \mathrm{~kJ} \mathrm{~mol}^{-1}\right)$, whatever the zeolite used. This remarkable constancy is illustrated in Figure 7 which shows the Arrhenius plot of intrinsic cracking rate constants obtained for the five alkanes over H-MFI(29). Comparison with the literature show that our values lie is in the low range of intrinsic activation energy value derived from the alkane adsorption heats and apparent activation energies (Table 4).9-10, 16 
Table 4. Comparison of intrinsic cracking rate parameters on H-MFI with previous experimental and theoretical studies. ${ }^{a}$

\begin{tabular}{|c|c|c|c|c|c|c|c|c|c|c|c|c|}
\hline \multirow{2}{*}{ 穿 } & \multirow{2}{*}{ 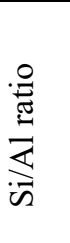 } & \multicolumn{4}{|c|}{ This work ${ }^{\underline{b}}$} & \multicolumn{2}{|c|}{$\begin{array}{c}\text { Narbesh- } \\
\text {-uber et } \\
\text { al. }{ }^{10}\end{array}$} & \multirow{2}{*}{\begin{tabular}{|l}
$\begin{array}{c}\text { Bhan et } \\
\text { al. }{ }^{9, c}\end{array}$ \\
$<\Delta S^{\ddagger}>$
\end{tabular}} & \multicolumn{2}{|c|}{$\begin{array}{l}\text { Tranca et } \\
\text { al. } 20, d\end{array}$} & \multicolumn{2}{|c|}{$\begin{array}{l}\text { Janda et } \\
\text { al. }{ }^{21, d, e}\end{array}$} \\
\hline & & $E_{\text {app }}$ & $E_{\mathrm{a}}$ & $\Delta S^{\dagger}$ & $<\Delta S^{\dagger}>$ & $E_{\text {app }}$ & $\mathrm{E}_{\mathrm{a}}$ & & $E_{\mathrm{a}}$ & & $E_{a}$ & $\Delta S^{\natural}$ \\
\hline & 20 & $151(2)$ & $189(4)$ & $-17(4)$ & $-23(4)$ & & & & & & & \\
\hline C3 & 29 & $151(1)$ & 192(3) & $-16(4)$ & $-21(4)$ & 155 & 198 & -9 & 185 & -68 & 198 & -21 \\
\hline & 75 & $151(4)$ & 189(2) & $-21(5)$ & $-26(5)$ & & & & & & & \\
\hline $\mathrm{C} 4$ & 29 & $134(2)$ & $188(4)$ & $-5(6)$ & $-15(6)$ & 135 & 197 & 3 & 186 & -65 & 188 & -25 \\
\hline & 20 & $122(2)$ & $189(6)$ & $-1(7)$ & $-13(7)$ & & & & & & & \\
\hline $\mathrm{C} 5$ & 29 & $120(5)$ & $186(6)$ & $-2(9)$ & $-13(9)$ & 120 & 194 & 11 & 176 & -35 & 183 & -23 \\
\hline & 75 & $123(2)$ & $186(5)$ & $-9(8)$ & $-20(8)$ & & & & & & & \\
\hline & 20 & $101(5)$ & 184(4) & $6(5)$ & $-7(5)$ & & & & & & & \\
\hline C6 & 29 & $98(1)$ & 183(4) & $2(6)$ & $-11(6)$ & 105 & 197 & 23 & 180 & -20 & 177 & -24 \\
\hline & 75 & $105(1)$ & 190(3) & $3(5)$ & $-10(5)$ & & & & & & & \\
\hline & 20 & $74(4)$ & $176(5)$ & $16(4)$ & 1(4) & & & & & & & \\
\hline C7 & 29 & $86(4)$ & $190(2)$ & $14(3)$ & $-1(3)$ & & & & & & & \\
\hline & 75 & $72(3)$ & 193(4) & $9(6)$ & $-6(6)$ & & & & & & & \\
\hline
\end{tabular}

${ }^{a}$ Activation energies in $\mathrm{kJ} \mathrm{mol}^{-1}$, activation entropies in $\mathrm{J} \mathrm{mol}^{-1} \mathrm{~K}^{-1} \cdot{ }^{b}$ Standard errors are in parentheses. ${ }^{\mathrm{c}}$ Computed from the experimental data of Narbeshuber et al. ${ }^{10}$ and Eder et al. ${ }^{6-7} d$ Computed from the reported values of $\Delta H^{*}$ at $773 \mathrm{~K}$ using $E_{\mathrm{a}}=\Delta H^{*}+\mathrm{RT}$. ${ }^{e}$ Computed from the apparent rate parameters of Narbeshuber et al. ${ }^{10}$ and adsorption parameters obtained by CBMC simulations. ${ }^{21-22}$ 


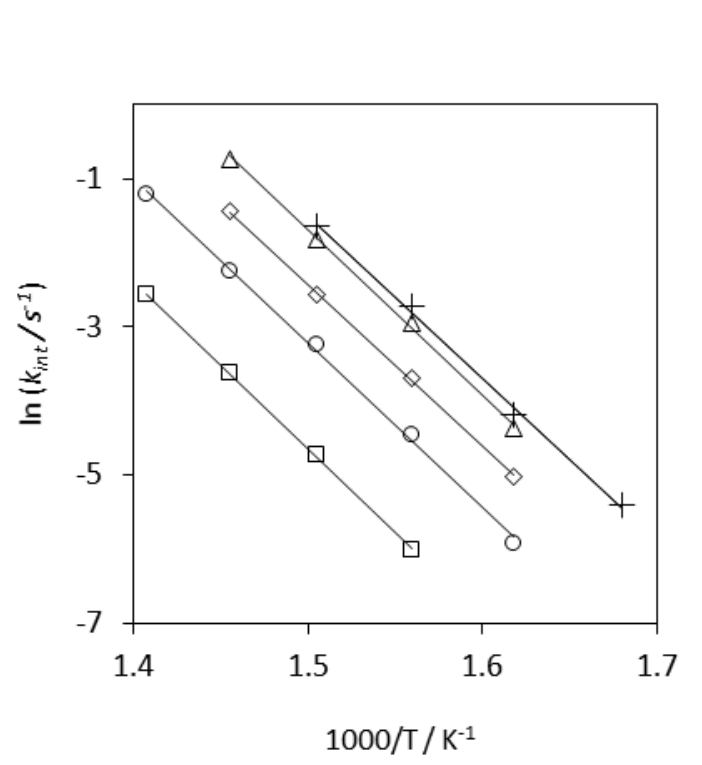

Figure 7. Arrhenius plots of intrinsic cracking rate constants of () propane, (o) n-butane, $(\diamond)$ n-pentane, $(\Delta)$ n-hexane and $(+)$ n-heptane cracking over H-MFI(29). Intrinsic rate is expressed in $\mathrm{s}^{-1}$.

Our data thus confirm that the intrinsic activation energies are independent of the chain length of the alkanes, and are consistent with previous experimental ${ }^{10}$ and most of theoretical ${ }^{18,20,32}$ studies. By contrast, in recent studies, ${ }^{21-22}$ Janda and coworkers have re-evaluated intrinsic activation energies by considering the experimental apparent activation energies on the one hand, and adsorption parameters issued from Monte Carlo simulations which selectively took into account the alkanes at the vicinity of the acid sites. As discussed in the previous section, this led to a much better agreement between predicted and observed adsorption entropies. However, Table 4 also shows that such an approach leads to a significant decrease of activation energies by $\sim 20 \mathrm{~kJ} \mathrm{~mol}^{-1}$ from propane to $\mathrm{n}$-hexane, which is not observed (Table 4 and Figure 7). This discrepancy suggests that not only the distance between the alkane and the $\mathrm{Al}$ atom should be 
taken into account. It is possible, in particular, that the directionality of the hydrogen bond should also be explicitly taken into account to characterize more selectively the reactant state.

By contrast with activation energy, the present data show that the magnitude of activation entropy increases with the chain length, in agreement previous studies. This confirms that differences in monomolecular cracking rates are primarily determined by the activation entropy affecting the intrinsic rate constant and not by differences in adsorption constants, that lead to similar reactant concentrations on the active sites at reaction conditions. ${ }^{9}, 16-17,20$ However, the magnitudes of intrinsic activation entropies derived by molecular simulation are markedly lower that those obtained here, or derived by Bhan et al. ${ }^{9}$, in particular for the lighter alkanes. As stated by Tranca at al., ${ }^{20}$ this difference could arise from the lower magnitude of adsorption entropies obtained from molecular simulation and discussed in the previous section, as compared to those obtained here. In the present work the actual concentration of alkane-acid site complexes at reaction conditions were determined, which is much lower than the concentrations predicted by the simulations of Tranca et al., ${ }^{20}$ and yields much higher intrinsic cracking rates and higher magnitudes of activation entropies. However, it should be also noted that the activation entropies reported by Tranca et al..$^{20}$ were obtained by DFT calculations where the initial reactant state was localized at the vicinity of the acid site. A major source of error could also be the method used to compute the entropy of the transition state, such as the harmonic approximation that could overestimate the contribution of soft, low frequency vibration modes. Finally, the intrinsic activation entropies recently re-evaluated by Janda and co-workers - from experimental rate constants and predicted adsorption parameters - have the same magnitudes as those determined here, but are nearly constant and do not predict the systematic increase with the alkane chain 
length. This again suggests that simulations should explicitly take into account the hydrogen bonding to describe the reactant state.

Finally, it is worth noticing that on the other side, the values of activation entropies determined in the present work at reaction conditions are also significantly lower than those obtained by combining low temperature adsorption experiments and classical activity measurements. ${ }^{9}$ However the magnitudes of adsorption entropies determined here were also found smaller than those of Eder et al. ${ }^{6-7}$ used in ref. ${ }^{9}$ (see Table 2) so that the apparent activation entropies, defined as the sum of adsorption and activation entropies, $\Delta S_{a p p}=\Delta_{\mathrm{ads}} S+\Delta S^{\ddagger}$ are in fair agreement. This suggests that the magnitudes of entropy of the hydrogen bonded state could be decreased at high temperature, as suggested by Tranca et al. ${ }^{20}$ though by a much lower amount than those predicted in this study.

In order to summarize these findings, the magnitudes of the various contributions of the enthalpic and entropic terms to the total apparent cracking rates can be conveniently represented using a waterfall chart of the natural logarithm of the cracking rate constant divided by the universal frequency factor $v$ :

$$
\ln \frac{k_{a p p}}{v}=-\frac{\Delta_{\mathrm{ads}} H}{\mathrm{RT}}+\frac{\Delta_{\mathrm{ads}} S}{\mathrm{R}}-\frac{E_{\mathrm{a}}}{\mathrm{RT}}+\frac{\Delta S^{\ddagger}}{\mathrm{R}}
$$

This is illustrated in Figure 8 for the cracking of $\mathrm{C}_{3}-\mathrm{C}_{7}$ linear hydrocarbons over H-MFI(29) for $\mathrm{T}=700 \mathrm{~K}$. In this representation, each term of Eqn. 16 is plotted sequentially for each hydrocarbon. Figure 7 shows the simultaneous increase of the magnitude of adsorption enthalpic and entropic terms with the hydrocarbon chain length which however compensate each other. The dotted line represents the natural logarithm of the adsorption constant $\left(\ln K_{\text {ads }}\right)$ which is nearly constant across the hydrocarbon series, clearly showing the compensation effect for adsorption. The largest term and main contributor to the magnitude of the apparent rate constants 
is the activation energy and is constant for the whole series of hydrocarbons investigated here. Finally, the activation entropic term is the smallest contribution to the apparent rate constants, but modulates and controls the wide range of cracking rates across the hydrocarbon series.

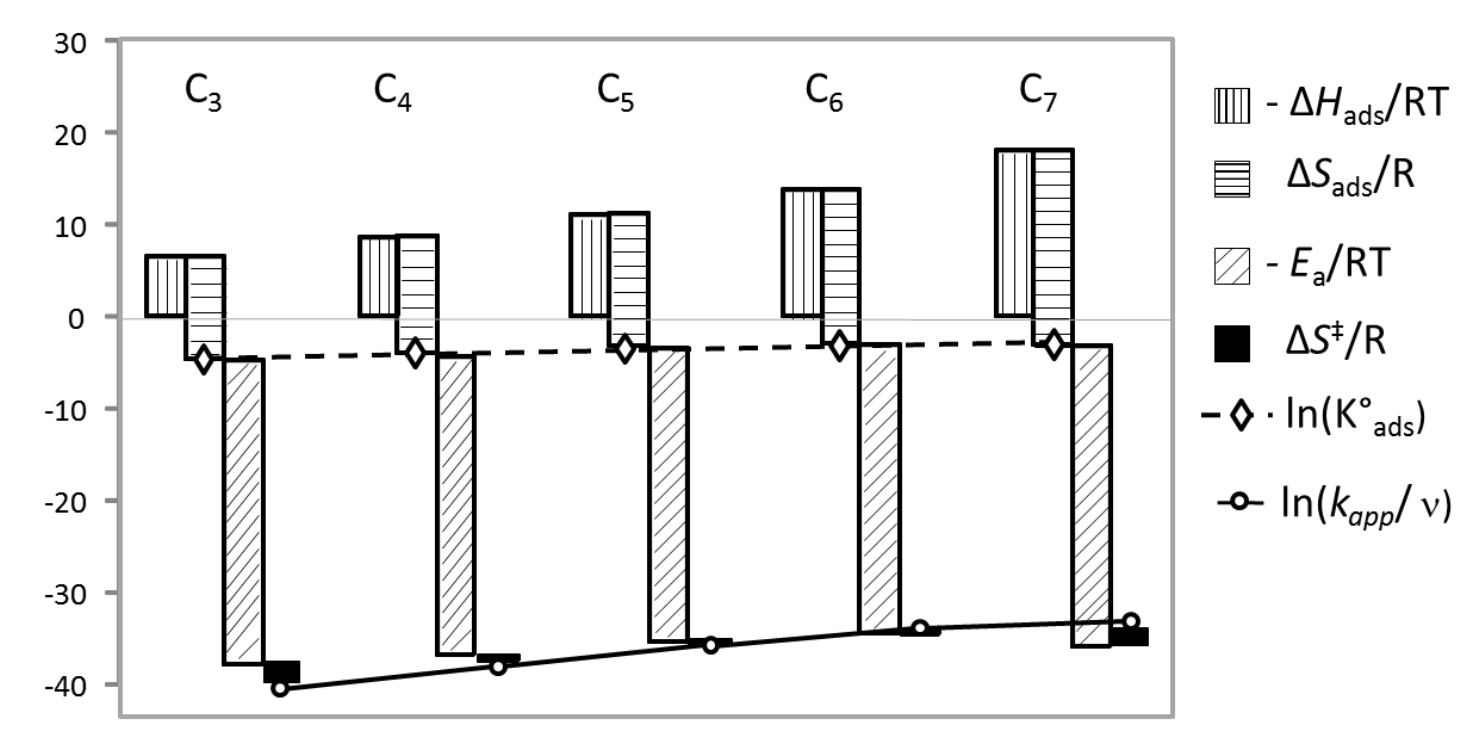

Figure 8. Waterfall plot of the adsorption and kinetic terms contributing to the adsorption constants and apparent rate constants for $\mathrm{H}-\mathrm{MFI}(29)$ at $\mathrm{T}=700 \mathrm{~K}$.

\section{Activation entropies of individual C-C cracking reactions.}

In the previous section, the kinetic parameters were determined for overall alkane monomolecular cracking. In this section the activation entropy of individual cracking reactions, which has not received much attention yet, are considered. Figure 9 shows the experimentally obtained selectivities toward lower alkanes for the monomolecular cracking of n-butane to nheptane plotted as a function of temperature. These selectivities are independent of temperature, indicating that the intrinsic activation energies for breaking different $\mathrm{C}-\mathrm{C}$ bonds within a given reactant molecule are the same, in agreement with previous studies. ${ }^{8,43}$ Thus, as for the overall cracking kinetics discussed above, the selectivities are also governed by the intrinsic activation 
entropies. Table 5 and Figure 10 show the experimental selectivities toward lower alkanes $\left(s_{i}\right)$ and the corresponding activation entropy values $\Delta S_{i}^{\ddagger}$ determined from the global activation entropies $\Delta S^{\ddagger}$ and the selectivities $s_{i}$ according to:

$$
\Delta S_{i}^{\ddagger}=\Delta S^{\ddagger}+R \ln s_{i}
$$
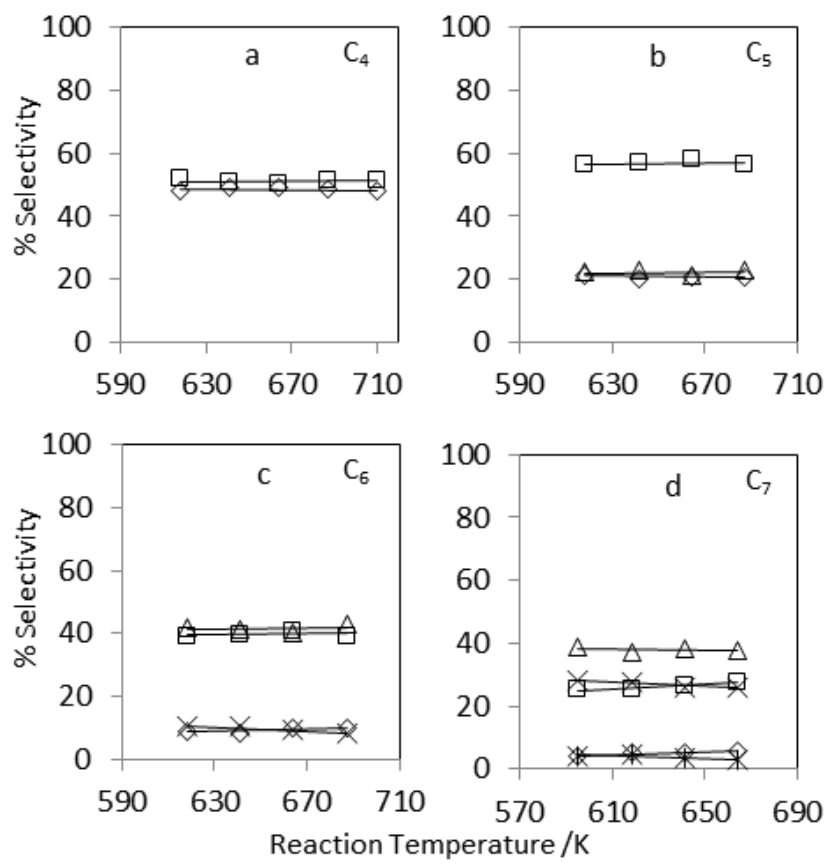

Figure 9. Alkane $\left(\mathrm{C}_{4}-\mathrm{C}_{7}\right)$ monomolecular cracking product selectivities on $\mathrm{H}-\mathrm{MFI}(29)$ plotted as a function temperature: $\mathrm{CH}_{4}(\diamond), \mathrm{C}_{2} \mathrm{H}_{6}(\square), \mathrm{C}_{3} \mathrm{H}_{8}(\Delta), \mathrm{C}_{4} \mathrm{H}_{10}(\circ)$ and $\mathrm{C}_{5} \mathrm{H}_{12}(\times)$. 

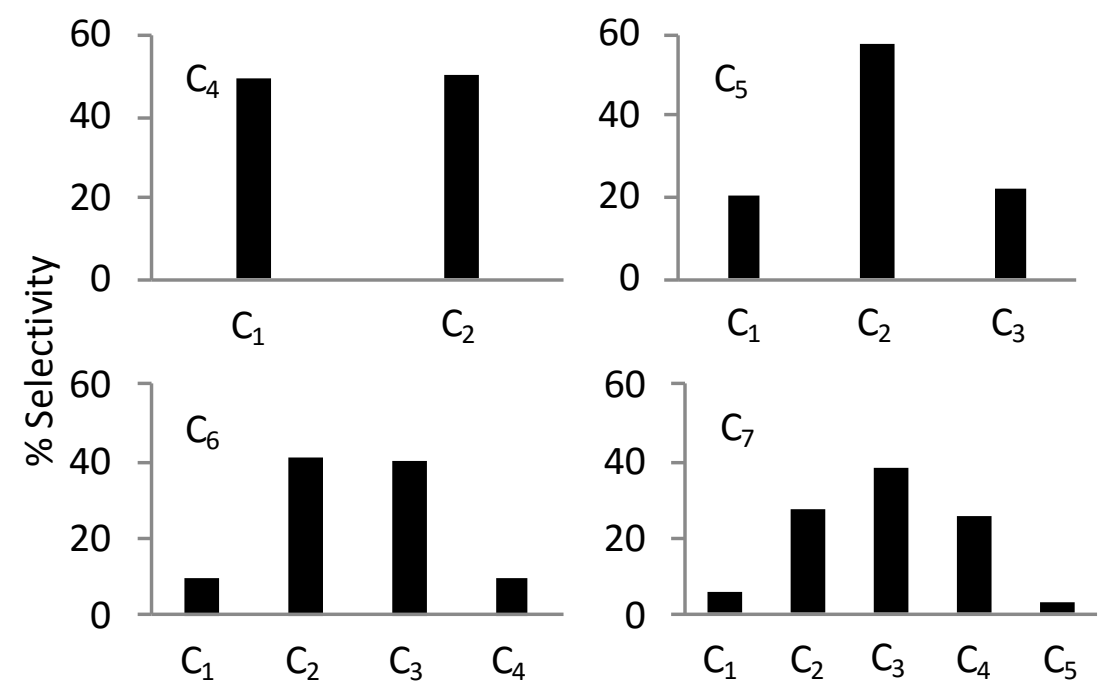

Figure 10. Selectivity towards lower alkanes during the monomolecular cracking of n-butane $\left(\mathrm{C}_{4}\right)$, n-pentane $\left(\mathrm{C}_{5}\right)$, n-hexane $\left(\mathrm{C}_{6}\right)$ and n-hepatne $\left(\mathrm{C}_{7}\right)$ on H-MFI(29) at $650 \mathrm{~K}$.

Table 5. Selectivities towards lower alkanes and associated activation entropies

\begin{tabular}{cccc}
\hline Reactant & Products & Selectivities $s_{i}$ & $\Delta \mathrm{S}^{\ddagger a}$ \\
\hline $\mathrm{C}_{4}$ & $\mathrm{CH}_{4}$ & 0.49 & -11 \\
& $\mathrm{C}_{2} \mathrm{H}_{6}$ & 0.51 & -11 \\
& & & \\
$\mathrm{C}_{5}$ & $\mathrm{CH}_{4}$ & 0.20 & -15 \\
& $\mathrm{C}_{2} \mathrm{H}_{6}$ & 0.58 & -6 \\
& $\mathrm{C}_{3} \mathrm{H}_{6}$ & 0.22 & -14 \\
& & & \\
$\mathrm{C}_{6}$ & $\mathrm{CH}_{4}$ & 0.10 & -17 \\
& $\mathrm{C}_{2} \mathrm{H}_{6}$ & 0.41 & -5 \\
& $\mathrm{C}_{3} \mathrm{H}_{6}$ & 0.40 & -5 \\
& $\mathrm{C}_{4} \mathrm{H}_{6}$ & 0.09 & -18 \\
& & & \\
$\mathrm{C}_{7}$ & $\mathrm{CH}_{4}$ & 0.06 & -10 \\
& $\mathrm{C}_{2} \mathrm{H}_{6}$ & 0.27 & 4 \\
& $\mathrm{C}_{3} \mathrm{H}_{6}$ & 0.38 & 8 \\
& $\mathrm{C}_{4} \mathrm{H}_{6}$ & 0.26 & 4 \\
& $\mathrm{C}_{5} \mathrm{H}_{12}$ & 0.04 & -13 \\
\hline
\end{tabular}

${ }^{\mathrm{a}}$ Values reported in $\mathrm{J} \mathrm{K}^{-1} \mathrm{~mol}^{-1}$ 
As shown by Figure 10, a very symmetric selectivity pattern is obtained when the lower alkane cracking products are ranked with the increasing chain length. As shown in the Supporting Information, similar patterns were consistently observed in many previous studies, irrespective of the type of zeolite used, as H-MFI ${ }^{5,8,11,43-48}$, H-MOR ${ }^{8,11,49}$, H-USY ${ }^{8,11,45,50}$ and chemically dealuminated HY. ${ }^{11}$

Table 5 shows that excepting for the cracking of central bonds of n-heptane, all C-C cracking reactions have negative activation entropies which implies the loss of degrees of freedom at the transition state with respect to the adsorbed, hydrogen-bonded state. For a given reactant, the close selectivities toward lower alkanes imply close entropies of the corresponding transition states. Recent state of the art theoretical studies generally show that the cracking reaction involves the scission of 3-center-two electrons carbocations to the products. ${ }^{18,32}$ Examination of Table 5 show that for a given reactant, products formed with similar selectivities are systematically produced from distinct carbocations. For instance, pentane cracking leads to methane and propane in nearly equal amounts ( 20 vs. $22 \%$, Table 5 ) while these products should result from the scission of distinct carbocations centers on the outer $\mathrm{C}_{1}-\mathrm{C}_{2}$ bond and the vicinal $\mathrm{C}_{2}-\mathrm{C}_{3}$ bond, respectively:

$$
\mathrm{C}-\mathrm{H}^{+}-\mathrm{C}-\mathrm{C}-\mathrm{C}-\mathrm{C} \rightarrow \mathrm{C}_{1}+\mathrm{C}_{4}=\text { and } \mathrm{C}-\mathrm{C}-\mathrm{H}^{+}-\mathrm{C}-\mathrm{C}-\mathrm{C} \rightarrow \mathrm{C}_{3}+\mathrm{C}_{2}=
$$

The scission of second carbocation can also lead to a distinct set of products, namely ethane and propene (C-C- $\left.\mathrm{H}^{+}-\mathrm{C}-\mathrm{C}-\mathrm{C} \rightarrow \mathrm{C}_{2}+\mathrm{C}_{3}{ }^{=}\right)$, but with significantly larger selectivity (58\% vs. $22 \%)$. It is striking that this can be generalized to all the products formed with similar selectivities. This shows that the entropy of the transition state does not primarily depend on the position of the three-center-two electrons carbocation in the molecule (in such a case $\mathrm{C}_{3}$ and $\mathrm{C}_{2}$ would be formed in close amount), but on the position of the carbon atom common to the $\mathrm{CC}$ 
bond to be broken and the vicinal $\mathrm{CC}$ bond that will belong to the product olefin. In the case of the two carbocations leading to methane and propane shown for pentane above, this corresponds to the second carbon of the chain, while for the carbocation leading to ethane, this corresponds to the third carbon atom of the chain. It thus appears that the transition states leading to the pairs of products symbolized in Scheme 1 below, where $j$ is the common atom of the bonds to be cleaved in the two sets of products with similar selectivities, have close entropies.

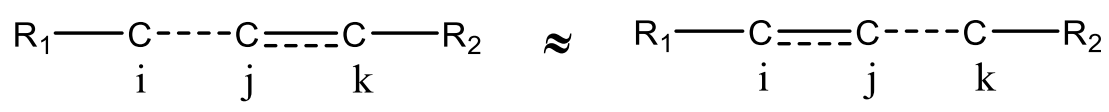

\section{Scheme 1}

Recent state-of-the art calculations have emphasized the complexity and multiplicity of reaction paths leading to a given set of products. ${ }^{18,32,51}$ Despite this complexity, however, the close entropies of transition states leading to products in Scheme 1 indicates that the partition functions associated to the internal degrees associated to bonds $\mathrm{i}-\mathrm{j}$ and $\mathrm{j}-\mathrm{k}-$ such as those associated to frustrated internal rotations - play a key role and have similar values at these distinct transition states.

\section{CONCLUSIONS}

In summary, the IR operando study of protolytic cracking of alkanes has allowed for the direct assessment of the intrinsic parameters of this reaction. Our results confirm that monomolecular cracking rates of alkanes are chiefly controlled by their intrinsic activation entropies at high temperature. IR spectroscopy allows for unambiguous definition and quantification of the initial state of the reaction, namely alkane - acid site hydrogen bond complexes at reaction conditions, which is key to properly quantify adsorption and activation entropic terms. While the activation entropies where found lower than those derived from low temperature adsorption measurement, they remain much higher than those currently predicted by state of the art calculations. 
With this respect, the present work could provide guidelines for theoretical predictions of alkane adsorption and reactivity on zeolites acid sites at elevated temperatures. Its application to other zeolite types and reactants should also give information as to what extent the present findings can be generalized to other reactions over acidic zeolites. ASSOCIATED CONTENT

Supporting Information. Additional experimental details, adsorption isotherms, and comparison of observed selectivities. "This material is available free of charge via the Internet at http://pubs.acs.org"

\section{AUTHOR INFORMATION}

\section{Corresponding Author}

* arnaud.travert@ensicaen.fr

\section{Author Contributions}

${ }^{\star}$ These authors contributed equally.

\section{Funding Sources}

The authors declare no competing financial interest.

\section{ACKNOWLEDGMENT}

S. Kadam thanks the EMC3 Excellence Laboratory for a PhD grant. R.F. Wormsbecher thanks Région Basse-Normandie and FEDER for a Chaire d'excellence. The authors thank Dr. F. Kaufmann for fruitful discussions. 


\section{REFERENCES}

(1) Degnan, T. F. Top. Catal. 2000, 13, 349-356.

(2) Vermeiren, W.; Gilson, J. P. Top. Catal. 2009, 52, 1131-1161.

(3) Cheng, W.-C.; Habib, T. E.; Kuppuswamy, R.; Roberie, T. G.; Wormsbecher, R. F.; Michael, Z. S. Fluid Catalytic Cracking. In Handbook of Heterogeneous Catalysis, Wiley-VCH Verlag GmbH \& Co. KGaA: 2008.

(4) Haag, W. O. Stud. Surf. Sci. Catal. 1994, 84, 1375-1394.

(5) Haag, W. O.; Dessau, R. M. In Proceedings of the 8th International Congress on Catalysis, Verlag Chemie: Weinheim, 1984; Vol. 2.

(6) Eder, F.; Lercher, J. A. Zeolites 1997, 18, 75-81.

(7) Eder, F.; Stockenhuber, M.; Lercher, J. A. J. Phys. Chem. B 1997, 101, 5414-5419.

(8) van Bokhoven, J. A.; Williams, B. A.; Ji, W.; Koningsberger, D. C.; Kung, H. H.; Miller, J. T. J. Catal. 2004, 224, 50-59.

(9) Bhan, A.; Gounder, R.; Macht, J.; Iglesia, E. J. Catal. 2008, 253, 221-224.

(10) Narbeshuber, T. F.; Vinek, H.; Lercher, J. A. J. Catal. 1995, 157, 388-395.

(11) Babitz, S. M.; Williams, B. A.; Miller, J. T.; Snurr, R. Q.; Haag, W. O.; Kung, H. H. Appl. Catal. A-Gen. 1999, 179, 71-86.

(12) Ramachandran, C. E.; Williams, B. A.; van Bokhoven, J. A.; Miller, J. T. J. Catal. 2005, 233, 100-108.

(13) Xu, B.; Sievers, C.; Hong, S. B.; Prins, R.; van Bokhoven, J. A. J. Catal. 2006, 244, $163-$ 168.

(14) Gounder, R.; Iglesia, E. Angew. Chem. Int. Ed. 2010, 49, 808-811.

(15) Bhan, A.; Iglesia, E. Acc. Chem. Res. 2008, 41, 559-567.

(16) Gounder, R.; Iglesia, E. Acc. Chem. Res. 2012, 45, 229-238.

(17) De Moor, B. A.; Reyniers, M. F.; Gobin, O. C.; Lercher, J. A.; Marin, G. B. J. Phys. Chem. C 2011, 115, 1204-1219.

(18) Bučko, T.; Benco, L.; Hafner, J.; Ángyán, J. G. J. Catal. 2011, 279, 220-228.

(19) Jiang, T.; Goltl, F.; Bulo, R.; Sautet, P. ACS Catalysis 2014, 4, 2351-2358.

(20) Tranca, D. C.; Hansen, N.; Swisher, J. A.; Smit, B.; Keil, F. J. J. Phys. Chem. C 2012, 116, 23408-23417.

(21) Janda, A.; Vlaisavljevich, B.; Lin, L.; Sharda, S.; Smit, B.; Head-Gordon, M.; Bell, A. J. Phys. Chem. C 2015, 119, 10427-10438.

(22) Janda, A.; Vlaisavljevich, B.; Lin, L.-C.; Smit, B.; Bell, A. J. Am. Chem. Soc. 2016, (in press, doi:10.1021/jacs.5b11355).

(23) Travert, A.; Maugé, F. Stud. Surf. Sci. Catal. 1999, 127 269-277

(24) Li, H.; Rivallan, M.; Thibault-Starzyk, F.; Travert, A.; Meunier, F. C. Phys. Chem. Chem. Phys. 2013, 15, 7321-7327.

(25) Wichterlova, B.; Tvaruzkova, Z.; Sobalık, Z.; Sarv, P. Microporous Mesoporous Mater. 1998, 24, 222-233.

(26) Thibault-Starzyk, F.; Gil, B.; Aiello, S.; Chevreau, T.; Gilson, J.-P. Microporous Mesoporous Mater. 2004, 67, 107-112.

(27) Madon, R. J.; Boudart, M. Ind. Eng. Chem. Fund. 1982, 21, 438-447.

(28) Gounder, R.; Iglesia, E. J. Am. Chem. Soc. 2009, 131, 1958-1971.

(29) Liu, D.; Bhan, A.; Tsapatsis, M.; Al Hashimi, S. ACS Catalysis 2010, 1, 7-17. 
(30) Wang, J.; Kispersky, V. F.; Nicholas Delgass, W.; Ribeiro, F. H. J. Catal. 2012, 289, 171178.

(31) Janda, A.; Bell, A. Journal of The American Cemical society 2013, 135, 19193-19207.

(32) Zimmerman, P. M.; Tranca, D. C.; Gomes, J.; Lambrecht, D. S.; Head-Gordon, M.; Bell, A. T. J. Am. Chem. Soc. 2012, 134, 19468-19476.

(33) Bordiga, S.; Lamberti, C.; Bonino, F.; Travert, A.; Thibault-Starzyk, F. Chem. Soc. Rev. 2015, 44, 7262-7341.

(34) van Bokhoven, J. A.; Tromp, M.; Koningsberger, D. C.; Miller, J. T.; Pietersez, J. A. Z.; Lercher, J. A.; Williams, B. A.; Kung, H. H. J. Catal. 2001, 202, 129-140.

(35) Tzoulaki, D.; Jentys, A.; Pérez-Ramírez, J.; Egeblad, K.; Lercher, J. A. Catal. Today 2012, 198, 3-11.

(36) Savara, A. J. Phys. Chem. C 2013, 117, 15710-15715.

(37) Swisher, J. A.; Hansen, N.; Maesen, T.; Keil, F. J.; Smit, B.; Bell, A. T. J. Phys. Chem. C 2010, 114, 10229-10239.

(38) Janda, A.; Bell, A. T. J. Am. Chem. Soc. 2013, 135, 19193-19207.

(39) Al-majnouni, K. A.; Yun, J. H.; Lobo, R. F. Chem CatChem 2011, 3, 1333-1341.

(40) Mallikarjun Sharada, S.; Zimmerman, P. M.; Bell, A. T.; Head-Gordon, M. J. Phys. Chem. C 2013, 117, 12600-12611.

(41) Krannila, H.; Haag, W. O.; Gates, B. C. J. Catal. 1992, 135, 115-124.

(42) Lercher, J. A.; van Santen, R. A.; vinek, H. Catalysis Letters 1994, 27, 91-96.

(43) Narbeshuber, T. F.; Brait, A.; Seshan, K.; Lercher, J. A. Appl. Catal. A-Gen. 1996, 146, 119-129.

(44) Lukyanov, D. B.; Shtral, V. I.; Khadzhiev, S. N. J. Catal. 1994, 146, 87-92.

(45) Corma, A.; Miguel, P. J.; Orchillés, A. V. J. Catal. 1997, 172, 355-369.

(46) Jolly, S.; Saussey, J.; Bettahar, M. M.; Lavalley, J. C.; Benazzi, E. Appl. Catal. A-Gen. 1997, 156, 71-96.

(47) Kotrel, S.; Rosynek, M. P.; Lunsford, J. H. J. Phys. Chem. B 1999, 103, 818-824.

(48) Jung, J. S.; Park, J. W.; Seo, G. Appl. Catal. A-Gen. 2005, 288, 149-157.

(49) Abbot, J.; Guerzoni, a. F. N. Appl. Catal. A-Gen. 1992, 85, 173-188.

(50) Williams, B. A.; Miller, J. T.; Snurr, R. Q.; Kung, H. H. Microporous Mesoporous Mater. 2000, 35-36, 61-74.

(51) Tranca, D. C.; Zimmerman, P. M.; Gomes, J.; Lambrecht, D.; Keil, F. J.; Head-Gordon, M.; Bell, A. T. J. Phys. Chem. C 2015, 119, 28836-28853. 
Table of Contents Graphic

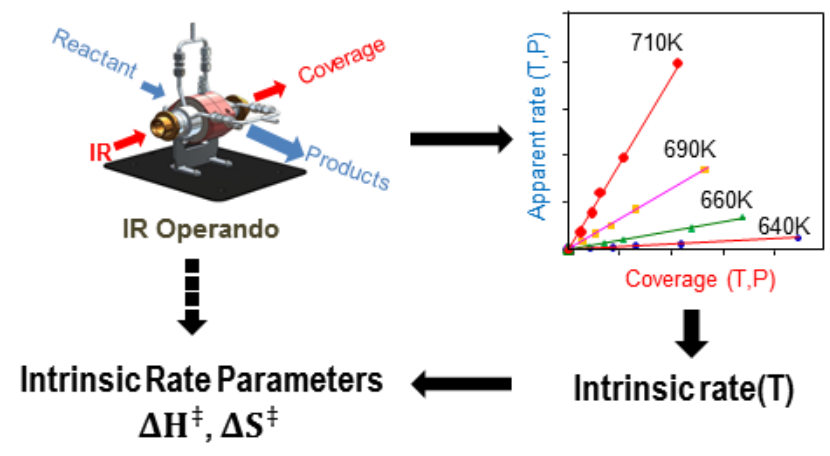

